\title{
Study of effects of repeated administration and withdrawal of cannabinoids on brain tissue of adult male albino rats: histopathological and biochemical study
}

\author{
Samy M. Badawy, Safaa A. Amin, Amira M. El-Seidy, Nagwa M. Habib and Reham Hassan. El- Farouny ${ }^{1}$, \\ ${ }^{1}$ Forensic Medicine and Clinical Toxicology Department, Faculty of Medicine, Menoufia University, Menoufia, Egypt.
}

\begin{abstract}
Introduction: Cannabis occupies the position of the most prevalent drug of abuse in Egypt. Chronic cannabis abuse may cause degenerative pathological changes in the brain, also the effect of cannabis on cognition, memory and learning is well known. The current work aimed to study the toxic effect of chronic repeated doses of cannabis on rat behavior, brain dopamine level and histopathological changes of the brain.

Subjects and Methods: The study was conducted on 50 male albino rats weighing 180-200 gm. Rats were divided into 2 main groups: group 1 (control; each animal received $1 \mathrm{ml} /$ day $100 \%$ sunflower oil (used as a vehicle); group 2 (received cannabis daily for one month " $40 \mathrm{mg}$ cannabis/ 200 gm rat". At the end of the month this group was subdivided into 4 subgroups: subgroups 2a, 2b, $2 \mathrm{c}$, and $2 \mathrm{~d}$ and subjected to different periods of cannabis abstinence. The clinical manifestations due to the effect of long-term cannabis administration and withdrawal were recorded. After scarification, brain dopamine level was measured, and brain tissue was examined by light and electron microscope (EM).

Results: Clinically; main manifestations of long-term cannabis administration found in subgroup 2a were CNS depression; while main manifestations in subgroup 2c were irritability and fighting aggression. Dopamine significantly increased in subgroup 2a compared to control group. Light and EM examination showed degenerative changes.

Conclusion: Brain dopamine level was significantly high in subgroup 2a compared with control group. long-term cannabis administration causes degenerative pathological changes in the brain, which need long recovery periods.
\end{abstract}

Key words Cannabis, dopamine, brain, $\Delta 9$ - THC

\section{Introduction}

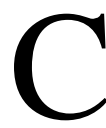

annabis consists of the leaves and flowering parts of the plant Cannabis Sativa and usually is smoked in cigarettes ("joints" or "reefers") or pipes or added to food (usually cookies or brownies).

Resin can be dried from the plant and packed int o blocks called hashish. Delta 9- tetrahydrocannabinol ( $\triangle 9$-THC) is the principal psychoactive ingredient of cannabis (Radwan et al., 2015). Common receptors for cannabinoids are CB1 and CB2. The receptors CB1 are primarily present in brain tissue and have a wide distribution. The highest densities are mainly located in the frontal cerebral cortex (higher functioning), hippocampus (memory, cognition), basal ganglia and cerebellum (movement), and striatum (brain reward) (Fitzgerald et al., 2013). In rodents CB1 receptor agonists as $\triangle 9$-THC, induce what has been called the "cannabinoid tetrad"; that is characterized by catalepsy, hypothermia, anti-nociception (blocking sensory neural perception of a harmful or injurious stimulus) and motor activity suppression (Katsidoni et al., 2013).

Chronic cannabis use can lead to dependence w hile stopping chronic use will $\mathrm{l}$ ad to symptoms of withdrawal (Ramesh et al., 2011). The diagnostic and statistical manual of mental disorders (DSM-5) listed cannabis as one of the addictive drugs and established medical criteria for "cannabis use disorder" (CUD) (American Psychiatric Association, 2013).

Human laboratory studies have shown that cannabinoid withdrawal syndrome has arisen after abrupt 
discontinuation of chronic oral $\Delta 9$-THC resulting in disturbed sleep, restlessness, irritability, vomiting, chills and nausea. It was therefore hypothesized that experience of physical withdrawal symptoms or concerns linked to abstinence may lead to the persistent use of marijuana in cannabis-dependent people (Lichtman and Martin, 2002; Allsop et al., 2011).

Cannabis use is associated with increased dopa mine levels, as one of the dependence drugs. Cannabinoi ds in fact cause their pharmacological activity by activati ng dopaminergic neurons in the brain more precisely; the mesostriatal dopaminergic system of cell bodies situated within the ventral tegmental area (VTA) and substantia nigra pars compacta (SNpc) by increasing the dopamine release in their corresponding dopamine terminal fields, nucleus accumbens (NAcc) and striatum (Fanarioti et al., 2015). The dopaminergic system has a crucial role in the production of addictive criteria of drugs and reward processing (Volkow et al., 2011), and it is involved in behavioral enhancement, motivated behavior and the modulation of violent behaviors (Rosell and Siever, 2015).

Chronic cannabis abuse can lead to neurodegenerative alterations that can be clarified by deposition of $\triangle 9$-THC in neurons leading to neurotoxic and neuroanatomic changes (Monnet-Tschudi et al., 2008). $\triangle 9$-THC is an important cause of oxidative cell stress that may lead to cell injury, metabolic dysfunction and neuronal harm (Sarafian and Marques, 1999).

The aim of the present study is to study the toxic effect of long term repeated doses of cannabis on rat behavior, brain dopamine level and histopathological changes of the brain; this may help in minimizing the use of this substance, which is considered safe by youth.

\section{Patients and Methods}

Drugs: Cannabis was obtained from a patient admitted to Dependence Treatment Unit- Forensic Medicine and Clinical Toxicology Department, Faculty of Medicine; Menoufia University for treatment. Cannabis was found with the patient during the routine inspection done before admission to Dependence Treatment Unit. It was a solid to resinous brown paste, about $10 \mathrm{gm}$. in weight. Cannabis was sent to the Forensic and analytical chemistry lab, Faculty of Medicine, Menoufia University to confirm its chemical identity (extraction and detection by thin layer chromatography (TLC) and was used in this study after getting permission of the head of department.

Calculation of cannabis dose: $\triangle 9$-THC was initially calculated at a dose of $10 \mathrm{mg} / \mathrm{kg}$ (i.e. $2 \mathrm{mg} \Delta 9-\mathrm{THC} / 200$ gm. rat) (Hložek et al., 2017). The doses used in the current study were selected according to animal and clinical studies in which $\Delta 9$-THC shows behavioral locomotor effects and induces psychotic-like symptoms in animals (Nagai et al., 2006; El-Alfy et al., 2010; Katsidoni et al., 2013; Wiley and Burston, 2014). Concentration of $\triangle 9$-THC in cannabis was measured by
TLC in comparison with standard curve; and was found to be $50 \mathrm{mg} \Delta 9$-THC / $1 \mathrm{gm}$. cannabis (i.e. $5 \%$ ). Then the corresponding daily cannabis dose was $=40 \mathrm{mg}$ cannabis/ 200 gm. rat (Hložek et al., 2017).

Animals: Study was conducted on 50 male albino rats weighing 180-200 gm., obtained from the breeding animal house in Menoufia University. Rats were kept in wide cages measuring $30 \times 60 \times 30 \mathrm{~cm}$; each one was able to accommodate 5 rats of approximately the same weight to simplify drug dosing calculation. They were left to acclimatize for one week. They were housed at room temperature in metallic cages and kept under constant healthy environmental and nutritional conditions. Rats were also kept under a schedule diurnal lightening conditions (12 hours for darkness and 12 hours for light). They were fed on dry food and housed under standard laboratory conditions. Initial weight of each animal was recorded at the beginning of the experiment and at its end (at the end of the month) for comparison. The maintenance of animals and the experimental procedures were in accordance with the guiding principles of Ethical Committee of Faculty of Medicine, Menoufia University.

Rats were divided into 2 main groups: group 1 (control group, consisted of 10 rats were kept throughout the experiment under the same conditions without any treatment and were given normal feeding to show the normal values of the tested parameters. Each animal received $1 \mathrm{ml} /$ day $100 \%$ sunflower oil (used as a vehicle) by a curved needle - like oral tube that was introduced directly into the stomach (a gavage process) (Hložek et al., 2017); group 2 (40 rats, received cannabis daily for one month "40 mg cannabis/ 200 gm rat, dissolved in sunflower oil $100 \%$ as a vehicle and given by an oral tube with gradually increasing dose by adding half of the initial calculated dose every 3 days till the end of the month". At the end of the month this group was further subdivided into 4 subgroups: subgroups 2a (10 rats, sacrificed after the last dose of cannabis i.e. under pharmacological effect of cannabis); subgroup $2 \mathrm{~b}$ (10 rats, left one day without giving cannabis after the last cannabis dose, and then sacrificed); subgroup 2c (10 rats, left 3 days without giving cannabis after the last dose, and then sacrificed); subgroup 2d (10 rats, left 7 days without giving cannabis after the last dose, and then sacrificed). After scarification, brain dopamine level was measured, and brain tissue was examined by both light and electron microscope.

Measurement of brain dopamine level: The hemisphere of the brain was homogenized each volume in 20 volumes of formic acid/ acetone (15/85, v/v), put in a glass centrifuge tube and shacked, centrifuged and the supernatant transferred to a glass centrifuge tubes. The supernatant was washed by shaking with $3 \mathrm{ml}$ of heptane/ chloroform (8/1, v/v) for every $1 \mathrm{ml}$ of formic acid/ acetone. The organic phase and lipid interfaces were aspirated, and the samples were left to dry. The samples were reconstituted 
in the dopamine assay buffer and analyzed by Infinite F50 TECAN ELISA (Smith et al., 1975).

Histopathology study: Hematoxylin and Eosin staining ( $H X$ \& E): (Jaffe, 1969; Carlton, 1982).

Histochemical Stain (Toluidine blue (T.B) stain): Nuclei and acid carbohydrate components are stained blue. Some carbohydrate- containing structures are metachromatically stained red. Cytoplasm RNA (e.g. Nissel bodies of neurons) is also blue (Kiernan, 1999). Transmission electron microscope (EM) examination of brain tissue was done in EM unit- Mansoura University for confirmation of findings detected by HX \& E and Toluidine blue stains (Reynolds, 1963; Karnovsky, 1965). Statistical Analysis:

Data were collected, organized, tabulated and statistically analyzed using Statistical Package for Social Science (SPSS) version 17 by Apple Mac computer. Both statistical analysis and tabulation were done according to (Dawson and Trapp, 2001). For quantitative data, for comparison of means of more than two groups one-way ANOVA test (f test) was used. the threshold of significance was fixed at $5 \%$ level ( $P$-value).

$P$ - Value of $>0.05=$ non-significant (NS).

$P$ - Value $<0.05=$ significant $(*)$.

\section{Results}

I) Observed Clinical Manifestations:

Group 1 (control group): No behavioral abnormalities were noticed.

Subgroups 2a: A dose-related CNS-depression within the first 10 days, progressed from inactivity to prostration, and was associated with incoordination and ataxia. Rats were hypoactive for 2-4 hours after giving the dose in the form of being not interested to food or looking from the cage to the foreigner as did the control group. Craving to cannabis occurred in all animals about 10-20 days after starting cannabis administration and this was known by observing the occurrence of mild withdrawal manifestations before giving the morning daily dose of cannabis (hyperactivity predominated in the form of irritability and tremors), which decreased after the dose intake. Decreased body weight was observed by approximately $10 \%$ from the weight at the beginning.

Subgroups 2b: at the end of the day at the time of cannabis dose; rats were hyperactive, irritable with scratching movements, facial rubbing, and licking.

Subgroups 2c: main manifestations were irritability, fighting aggression, beating each other. Chewing movement and salivation were observed. Gasps and shakes (both head shakes and body shakes) were recorded. Cheek tremors and teeth chattering were also seen.

Subgroups 2d: irritability markedly decreased, rats were relatively more calm, with more improved appetite for food.

Table 1 shows comparison of brain dopamine level between different groups of experimental albino rats: dopamine significantly increased in subgroup 2a (under pharmacological effect of cannabis) compared to control group; and significantly decreased in subgroup 2d (withdrawal of cannabis for 7 days) compared to subgroup 2a.

II) Brain dopamine level:

Table 1: Comparison of brain dopamine level between different groups in experimental albino rats using one-way ANOVA test (f test):

\begin{tabular}{|c|c|c|c|c|c|}
\hline $\begin{array}{c}\text { Brain dopamine } \\
\text { level (ng/ml) }\end{array}$ & G1 (control) & $\begin{array}{c}\text { Subgroup 2a } \\
\text { (under effect) }\end{array}$ & $\begin{array}{c}\text { Subgroup 2b } \\
\text { (withdrawal 1day) }\end{array}$ & $\begin{array}{c}\text { Subgroup 2c } \\
\text { (withdrawal 3 } \\
\text { days) }\end{array}$ & $\begin{array}{c}\text { Subgroup 2d } \\
\text { (withdrawal 7 } \\
\text { days) }\end{array}$ \\
\hline Mean \pm S.D & $0.12 \pm 0.1$ & $1.27 \pm 0.04$ & $0.87 \pm 0.43$ & $0.76 \pm 0.12$ & $0.34 \pm 0.14$ \\
\hline Range & $0.05-0.19$ & $1.25-1.30$ & $0.56-1.18$ & $0.68-0.85$ & $0.24-0.45$ \\
\hline \multirow{3}{*}{$\boldsymbol{P}$ value } & $\mathbf{P}$ value & $* \mathbf{0 . 0 0 3}$ & $* \mathbf{0 . 0 1 9}$ & $* \mathbf{0 . 0 3 2}$ & 0.353 \\
\cline { 2 - 6 } & & $\mathbf{P}$ value & 0.125 & 0.069 & $* \mathbf{0 . 0 0 8}$ \\
\cline { 2 - 6 } & & & $\mathbf{P}$ value & 0.659 & 0.061 \\
\cline { 2 - 6 } & & & $\boldsymbol{P}$ value & 0.110 \\
\hline
\end{tabular}

${ }^{*} P$ value $<0.05=$ significant $\quad P$ value $>0.05=$ non-significant 


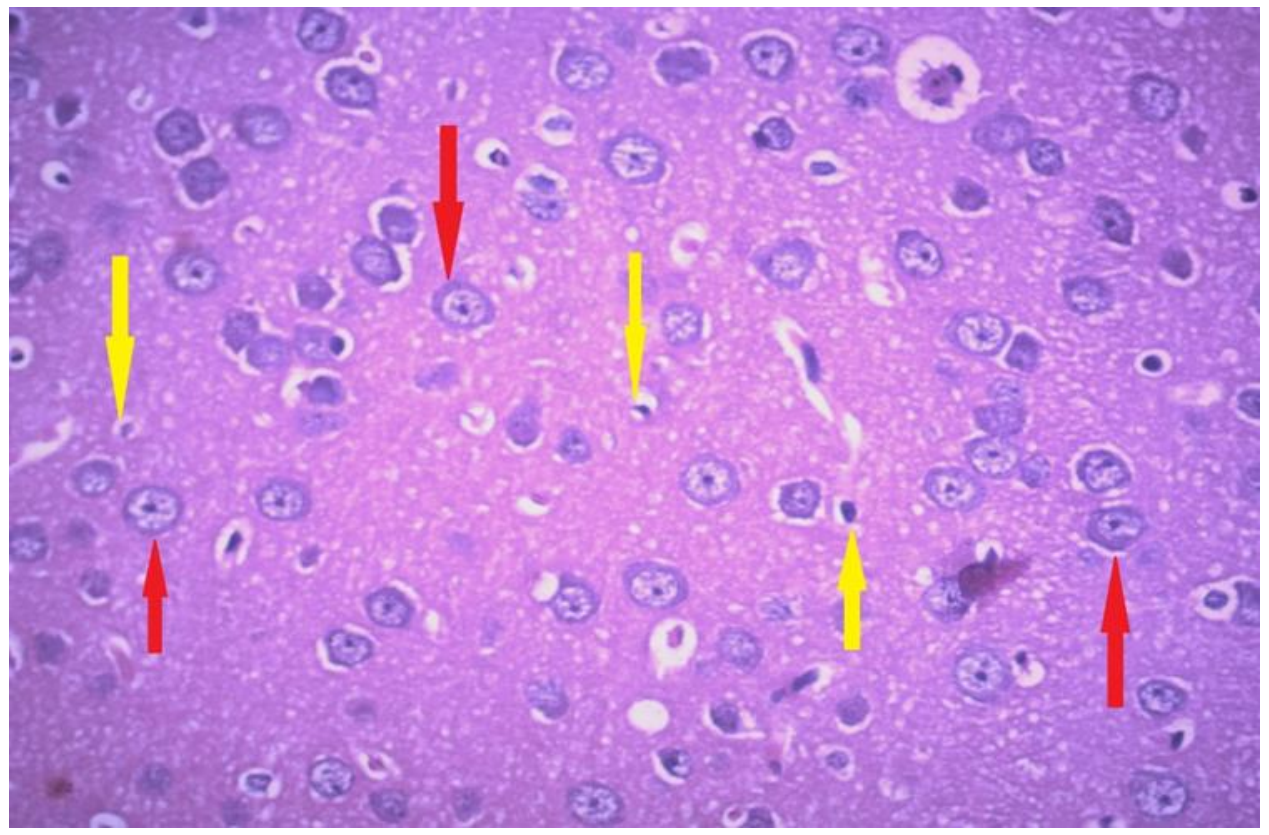

Fig. 1: A photomicrography of brain tissue of rats group 1 (control) showing normal brain tissue with normal neurons which exhibit vesicular nuclei (red arrow) and normal neuroglia cells which exhibit darkly stained nuclei (yellow arrow) (H \&E,X 400)

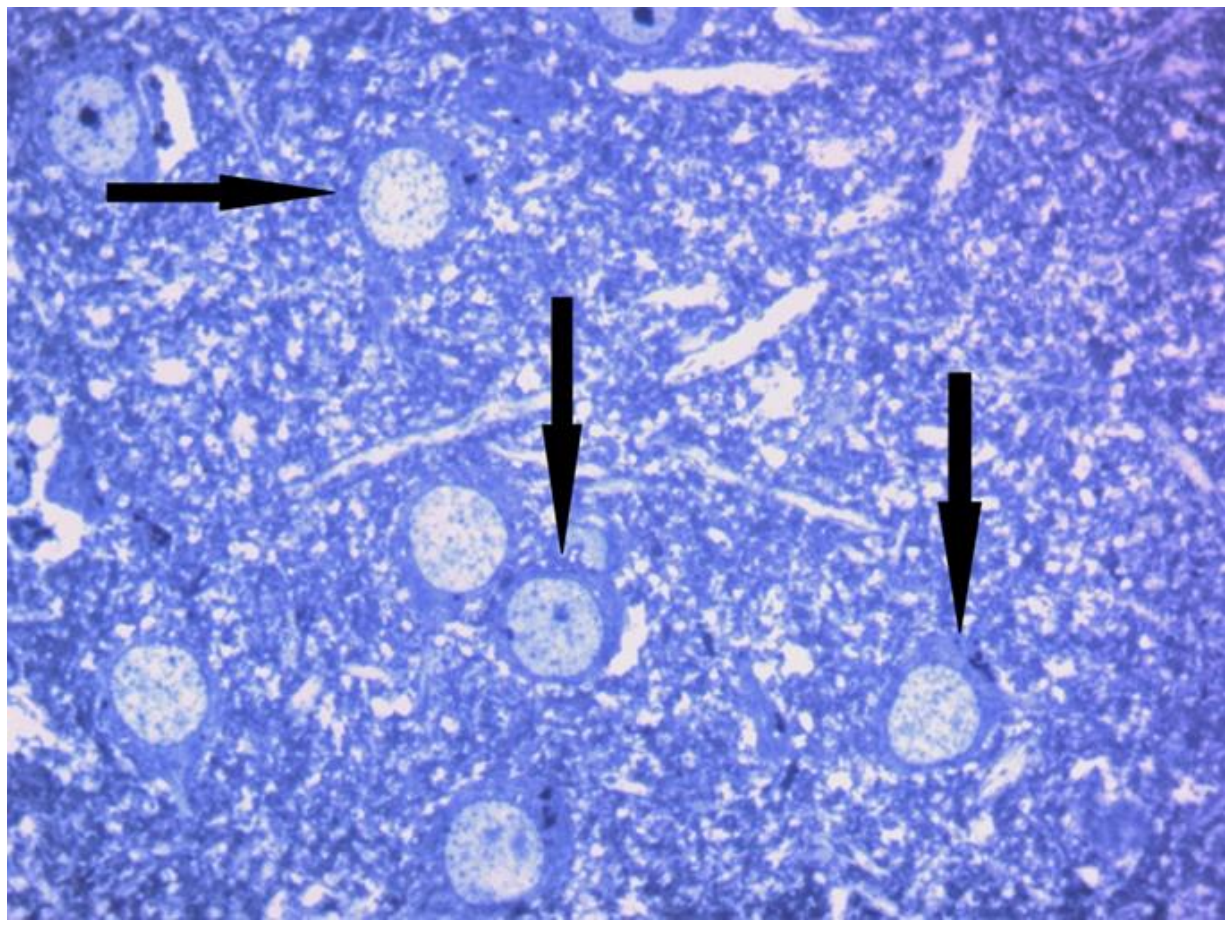

Fig. 2: A photomicrography of brain tissue of group 1 (control) showing the normal appearance of neurons with vesicular open face nuclei and blue stained nissl granules in the cytoplasm (arrow) (T.B X 1000) 


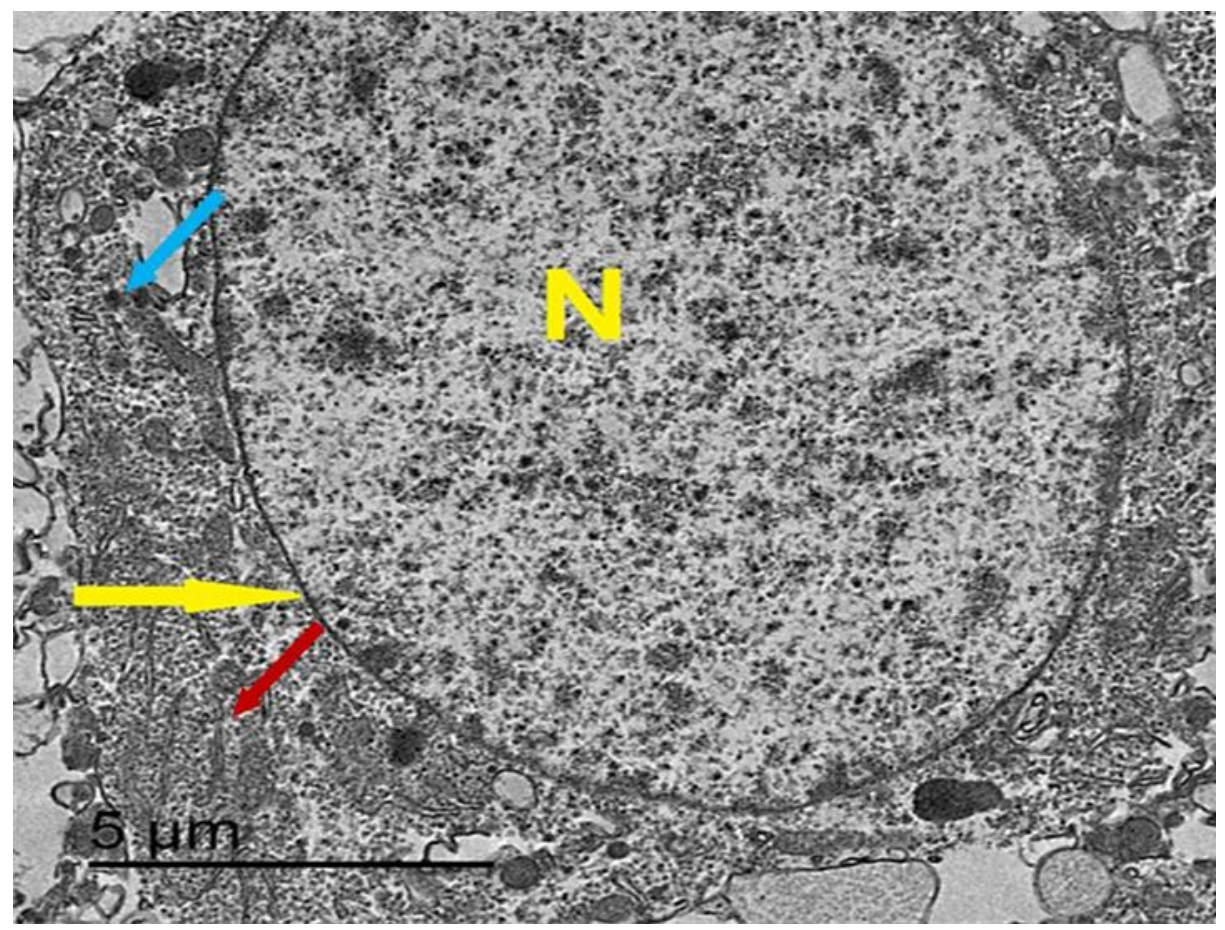

Fig. 3: A photomicrography of ultrathin sections of brain tissue of group 1 (control) showing a normal neuron, with euchromatic nucleus $(\mathrm{N})$, regular nuclear membrane (yellow arrow) and normal mitochondria (blue arrow) and RER (red arrow) (EM 1200)

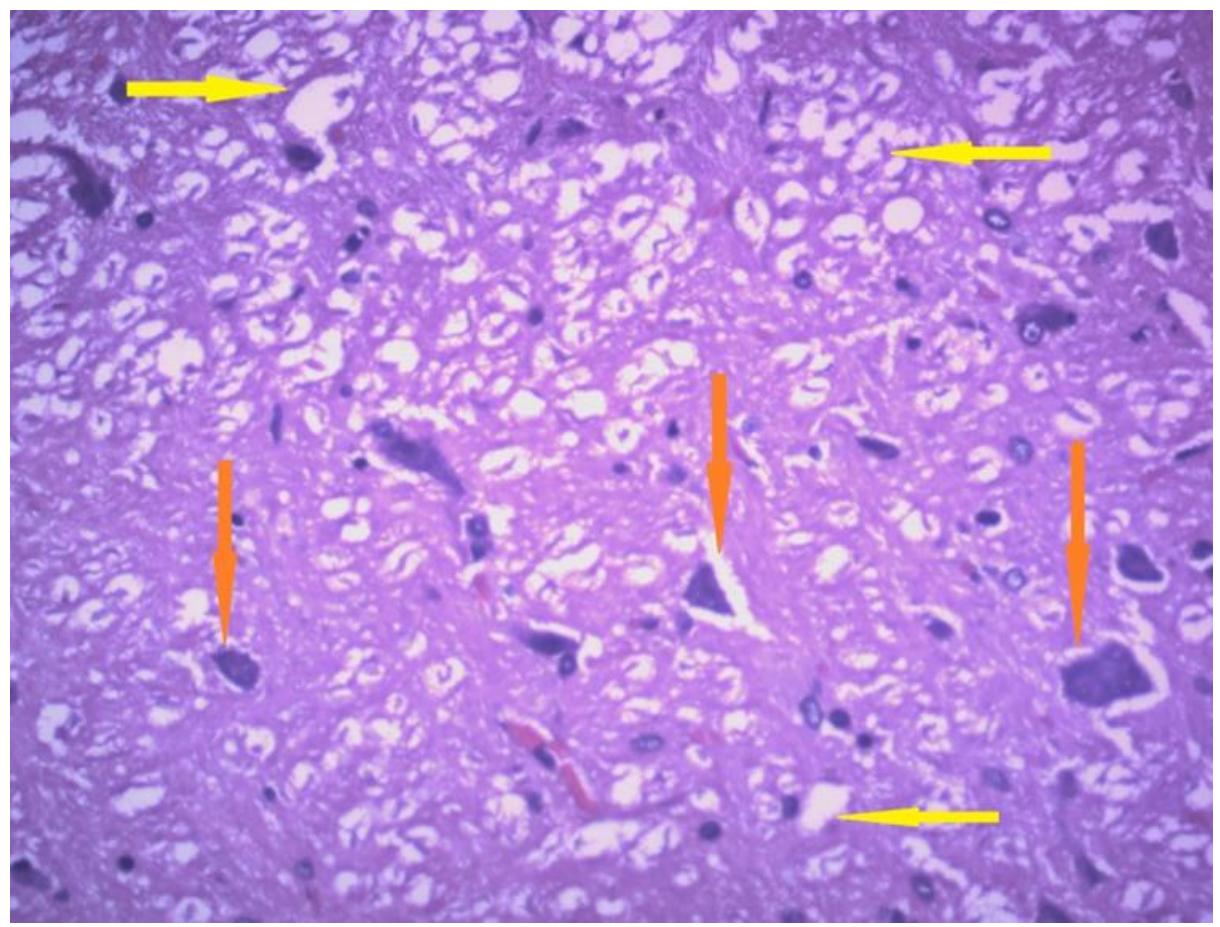

Fig. 4: A photomicrography of brain tissue of subgroup 2a (under effect of cannabis) showing degenerative changes in the neurons of cerebrum which appear darkly stained (orange arrow). Edema fluid is observed splitting the substance of the brain (yellow arrow) (H\&E, X 400) 


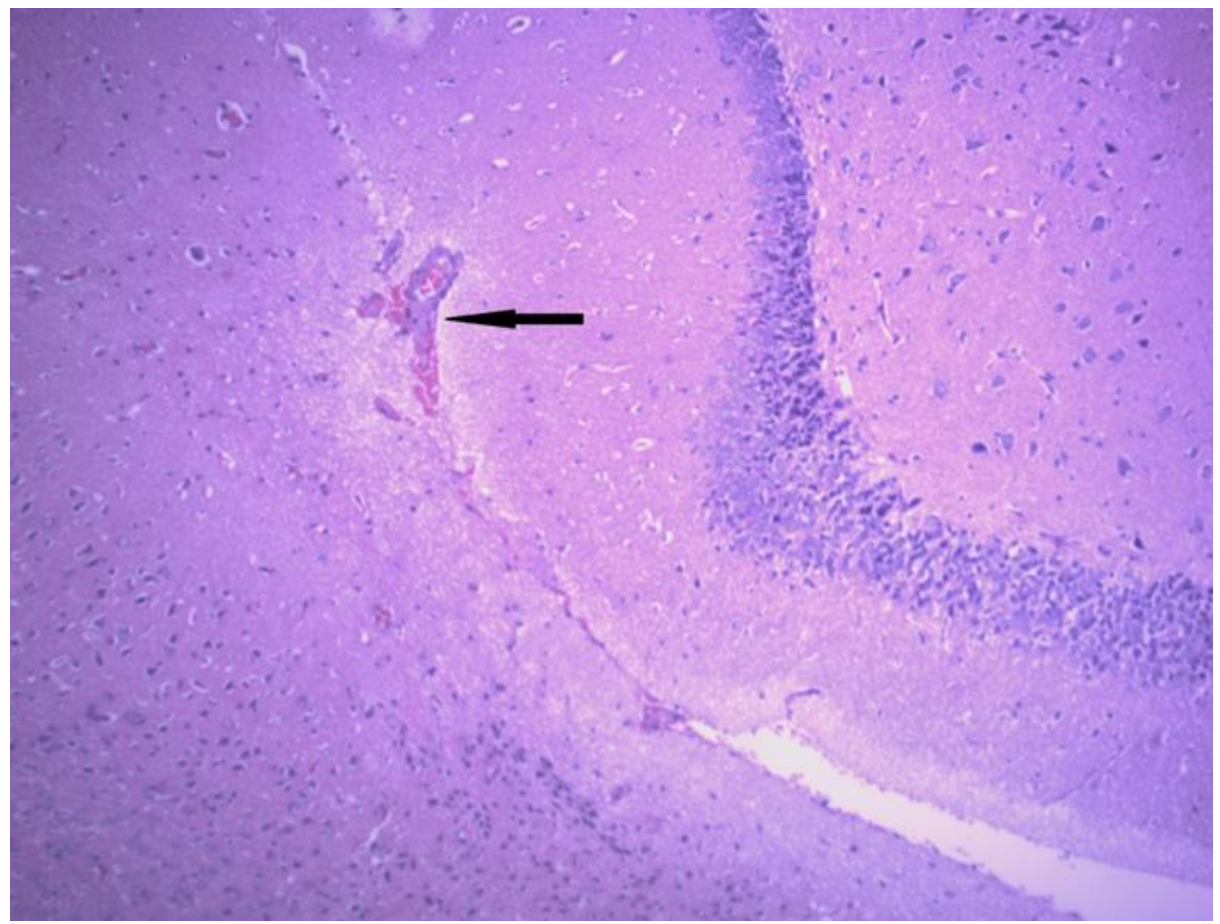

Fig. 5: A photomicrography of cerebellum of subgroup 2a (under effect of cannabis) showing congestion and extravasation of blood in the brain tissue together with edema fluid infiltration around the congested vessels (black arrow) (H\&E, $X$ 100)

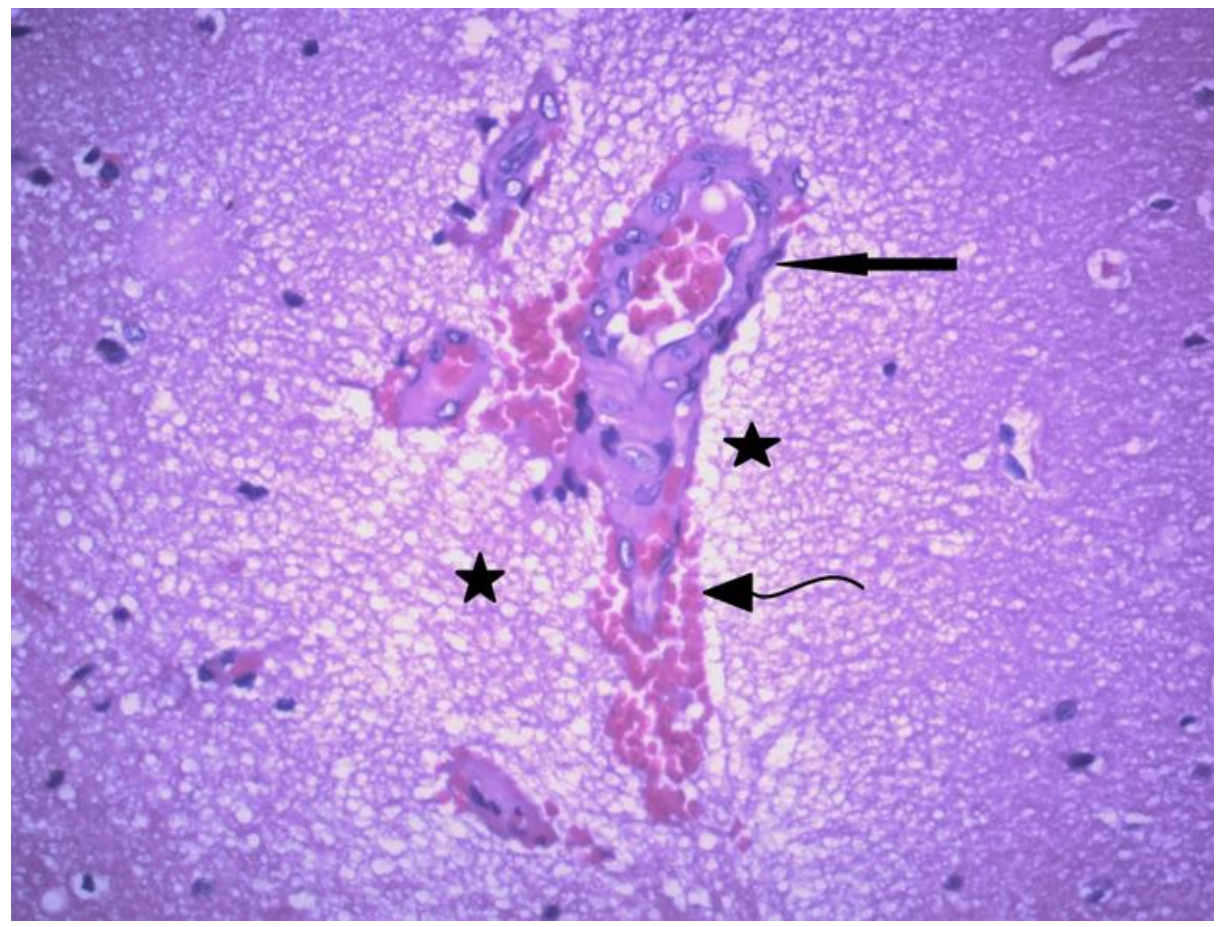

Fig. 5: A photomicrography of cerebellum of subgroup 2a (under effect of cannabis) showing magnification of fig 5 to demonstrate congestion (arrow) and extravasation of blood (curved arrow) in the brain tissue together with edema fluid infiltration (star) around the congested vessels (H\&E, X 400) 


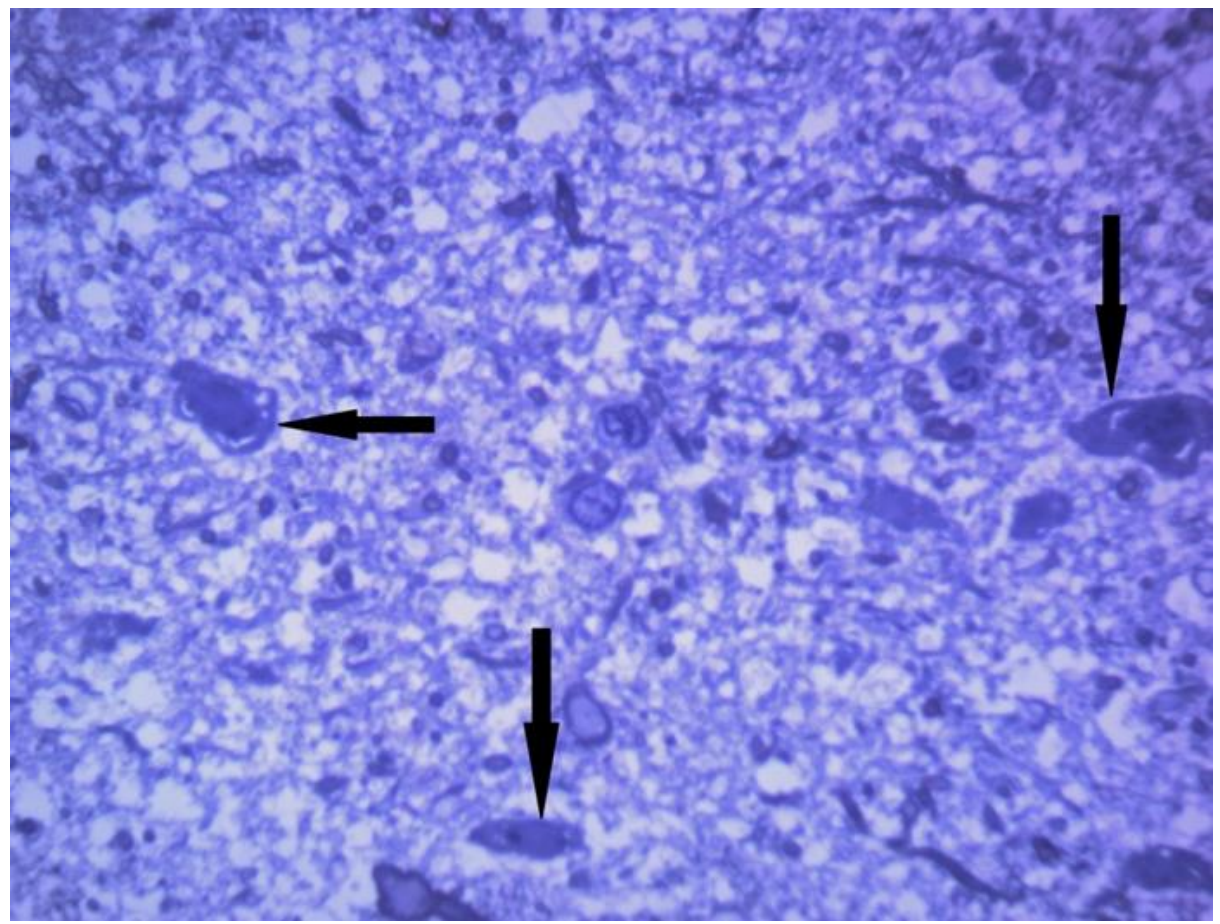

Fig. 6: A photomicrography of brain tissue of subgroup 2a (under effect of cannabis) showing degenerated neurons with irregular cell boundaries and darkly stained nuclei (arrow)

(T.B X 400)

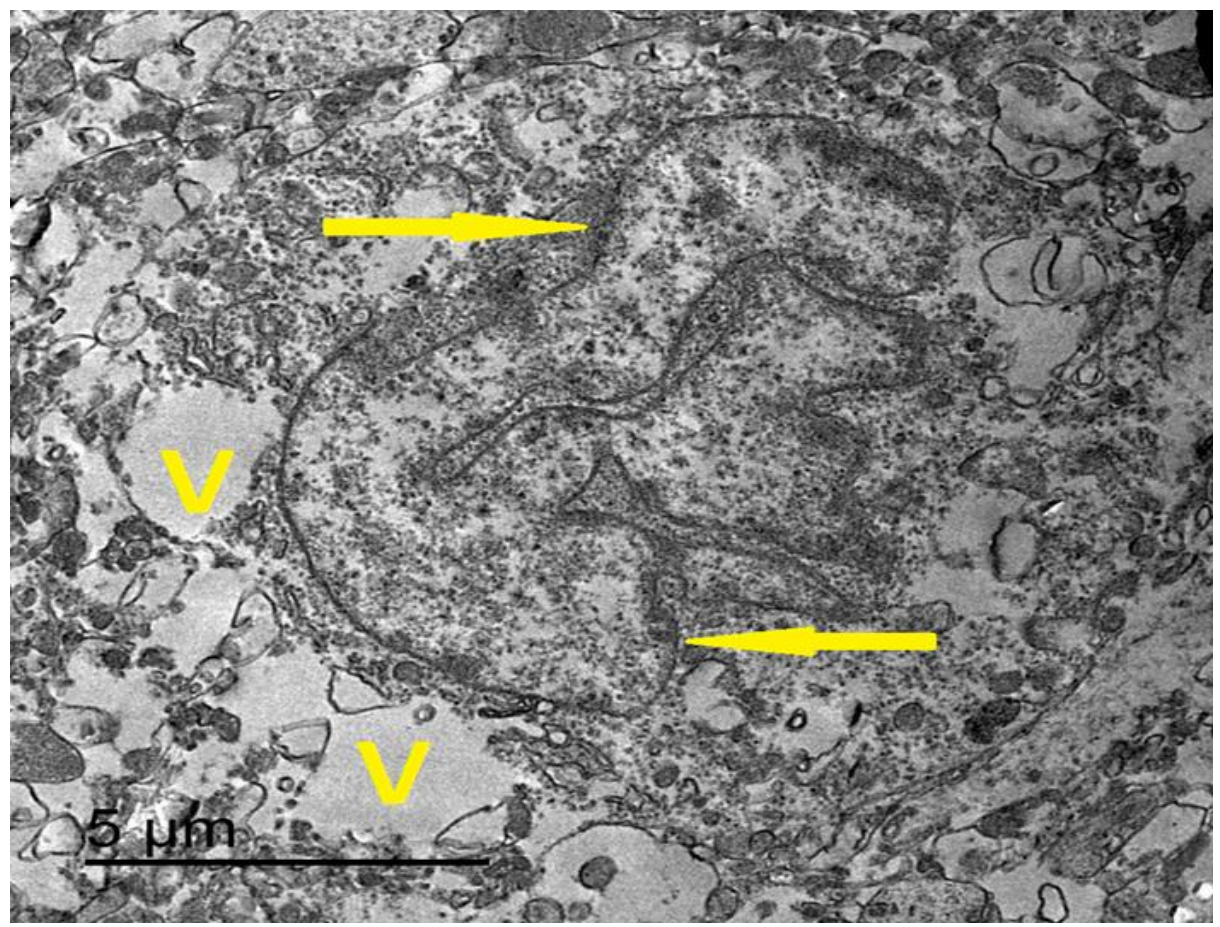

Fig. 7: A photomicrography of ultrathin sections of brain tissue of subgroup 2a (under effect of cannabis) showing degenerative changes in the form of nuclear membrane folding (arrow) with multiple vacuoles in the cytoplasm (V) (EM 1200) 


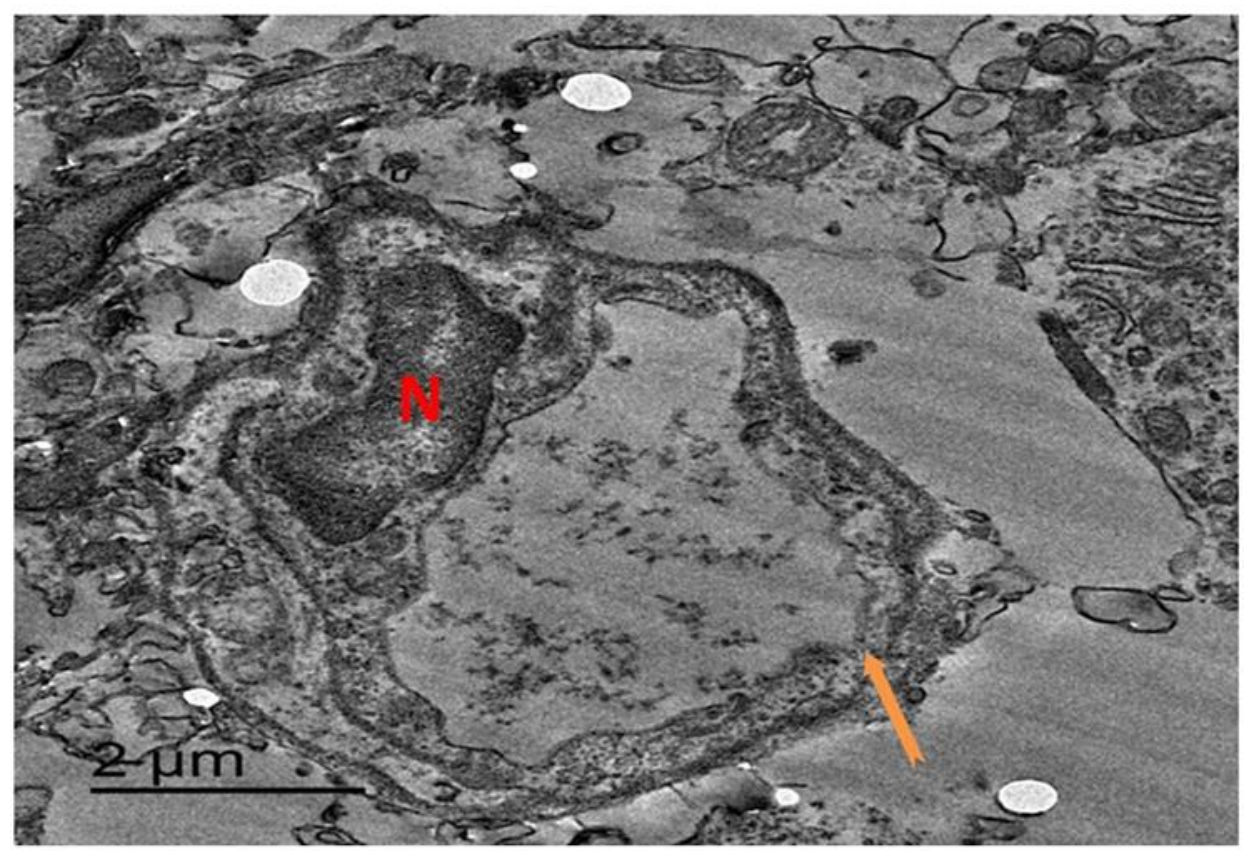

Fig. 8: A photomicrography of ultrathin sections of brain tissue of subgroup 2a (under effect of cannabis) revealed a blood vessel with disrupted tight junction of endothelial cell (arrow). Notice endothelial cell with electron dense nucleus $(\mathrm{N})$ and irregular nuclear membrane (EM 1200)

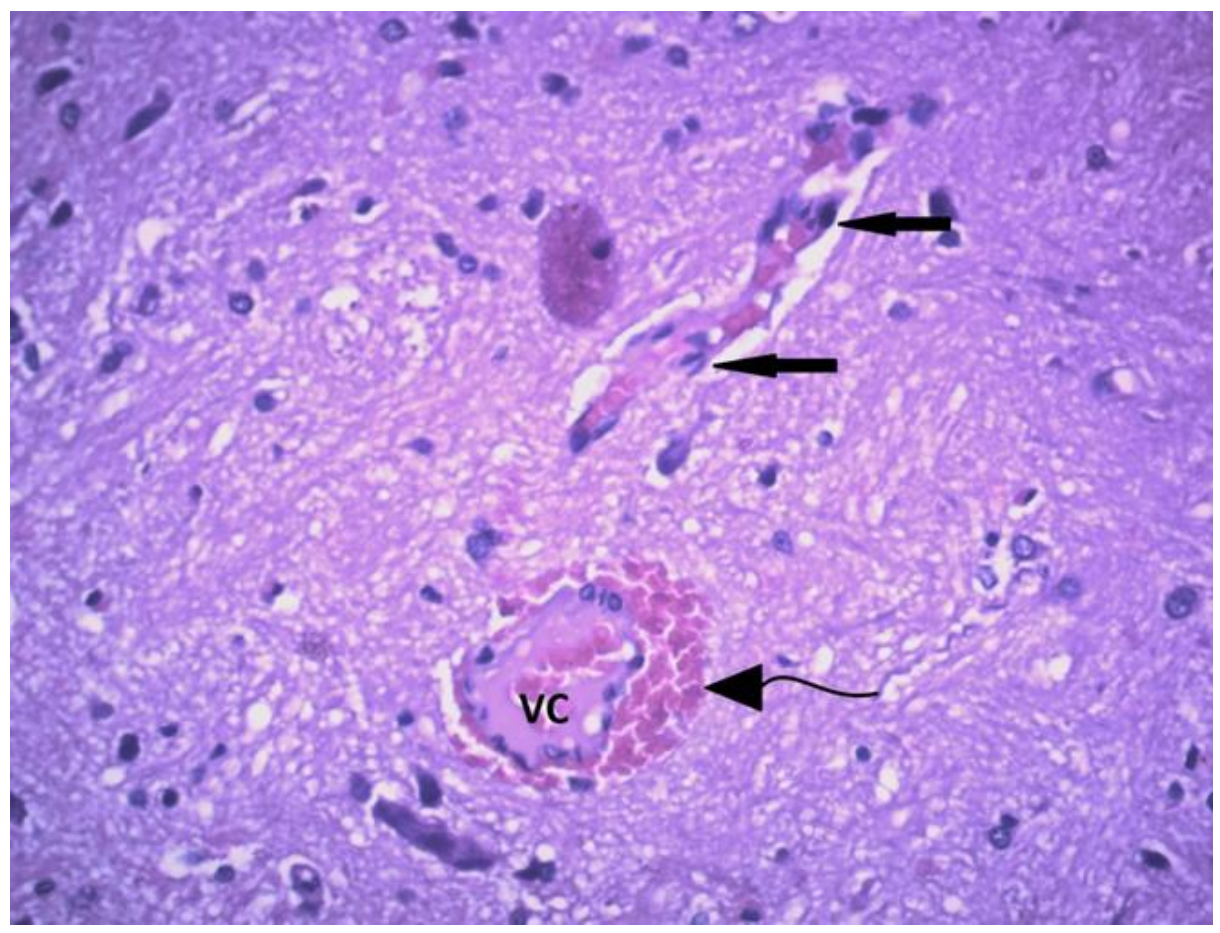

Fig. 9: A photomicrography of brain tissue of subgroup $2 b$ (withdrawal of cannabis for 1 day) showing no improvement compared with subgroup 2a. Notice the vascular congestion with extravasation of blood in the brain tissue around the congested vessels (curved arrow). Notice also sloughing of capillary endothelium (arrow) (H\&E, X 400) 


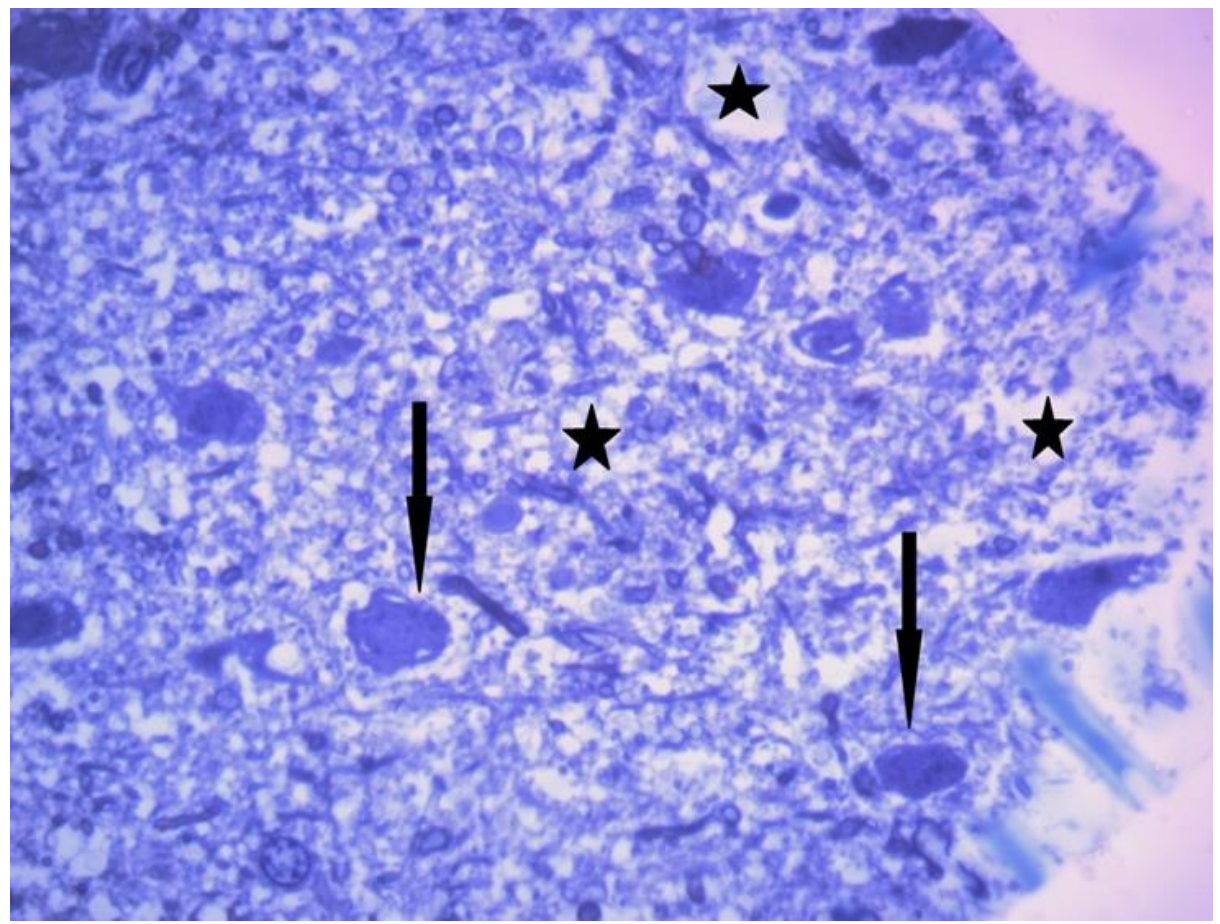

Fig. 10: A photomicrography of brain tissue of subgroup $2 b$ (withdrawal of cannabis for 1 day) showing no improvement of the histological picture. Most of the neurons appear degenerated with irregular cell boundaries and dark stained nuclei (arrow). Edema fluid still infiltrates the brain substance (star) (T.B X 400)

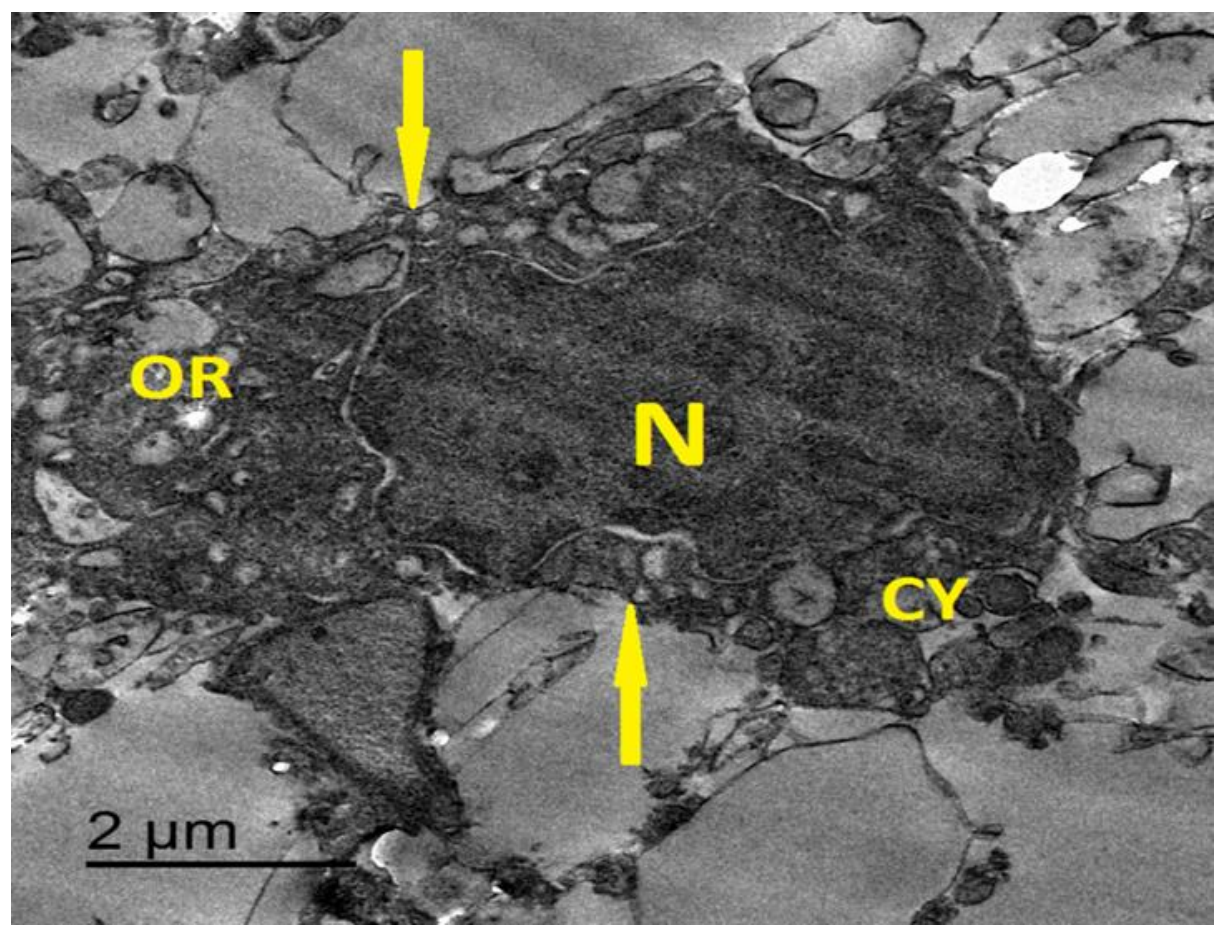

Fig. 11: A photomicrography of ultrathin sections of brain tissue of subgroup $2 b$ (withdrawal of cannabis for 1 day) revealed no improvement compared to subgroup 2a. A degenerated neuron appears with pyknotic nucleus $(\mathrm{N})$, shrunken cytoplasm (CY) and degenerated organelles (OR) 


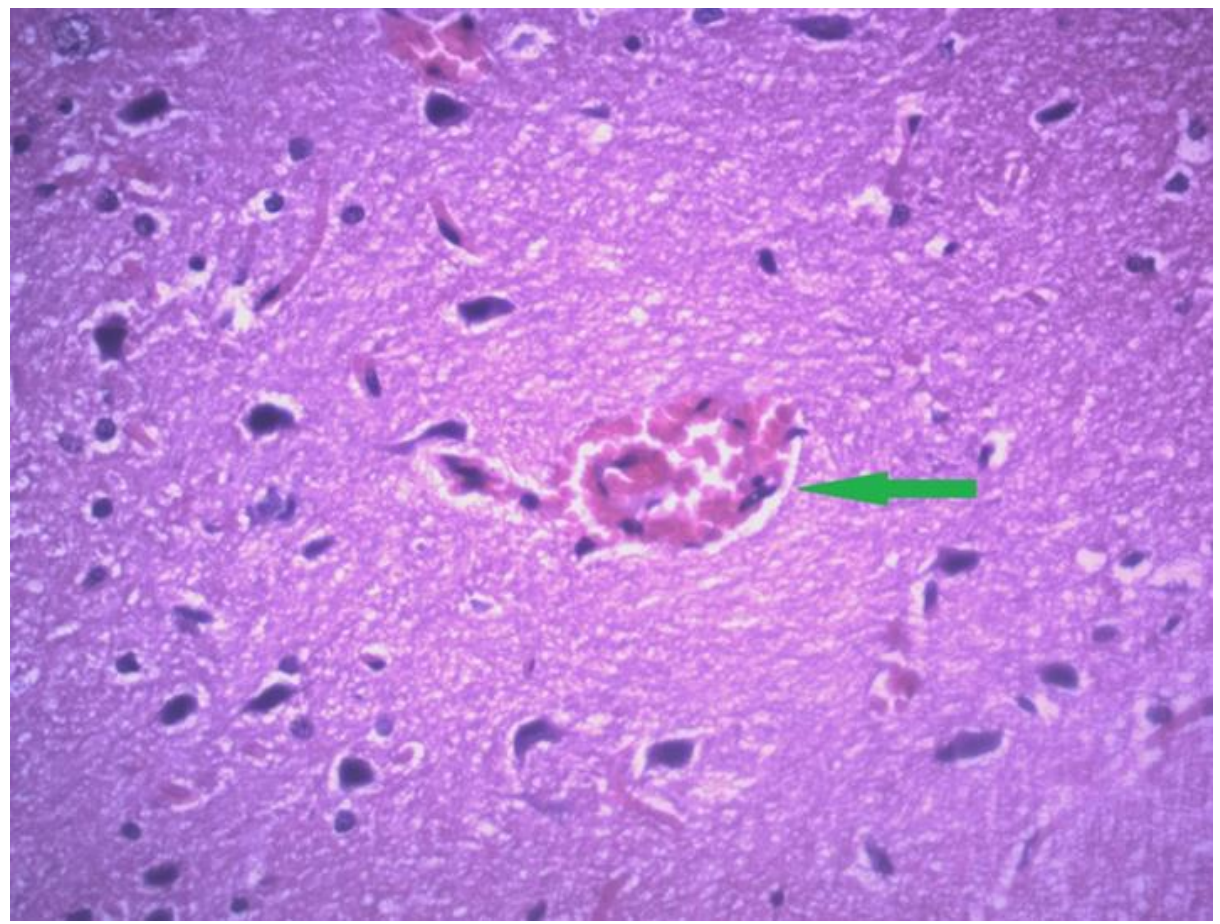

Fig. 12: A photomicrography of brain tissue of subgroup 2c (withdrawal of cannabis for 3 days) showing area of hemorrhage in the brain substance (arrow) (H\&E, X 400)

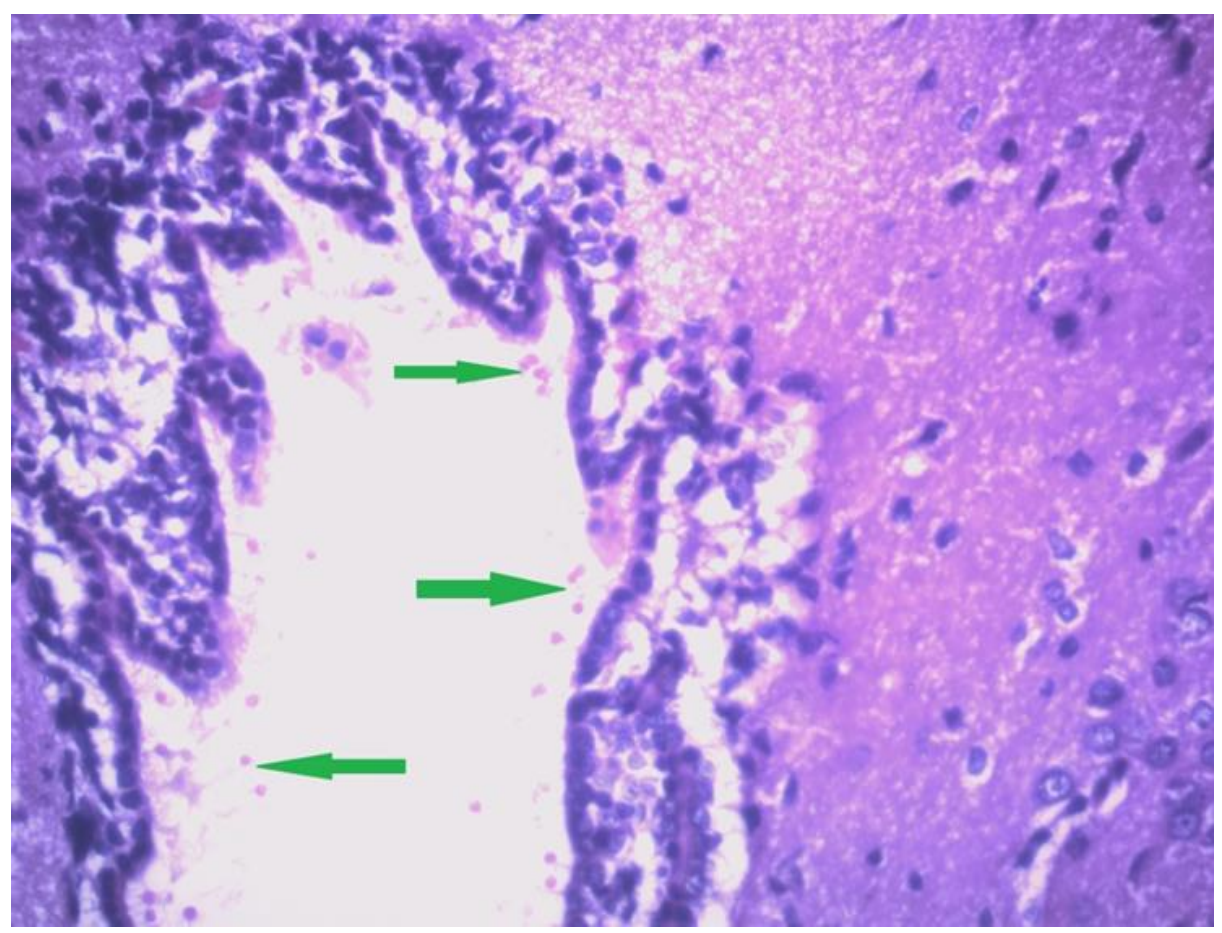

Fig. 13: A photomicrography of brain tissue of subgroup 2c (withdrawal of cannabis for 3 days) showing stagnation of RBCs in the cavity of the brain ventricles (arrow) (H\&E, X 400) 


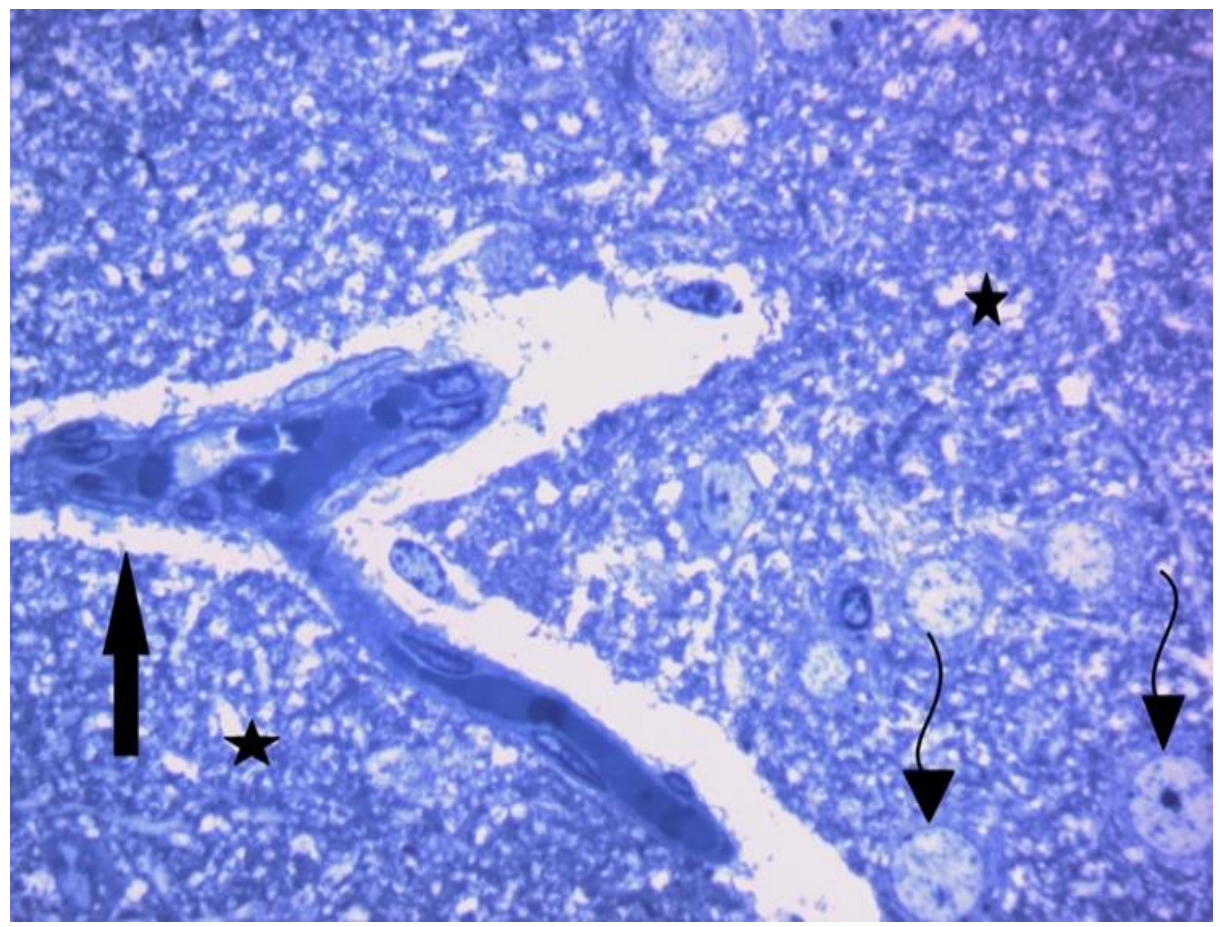

Fig. 14: A photomicrography of brain of subgroup 2c (withdrawal of cannabis for 3 days) showing mild improvement, some neurons appear normal with vesicular open face nuclei (curved arrow) while others appear degenerated. Notice also the vascular congestion (arrow) and edema infiltration (star) (T.B X 1000)

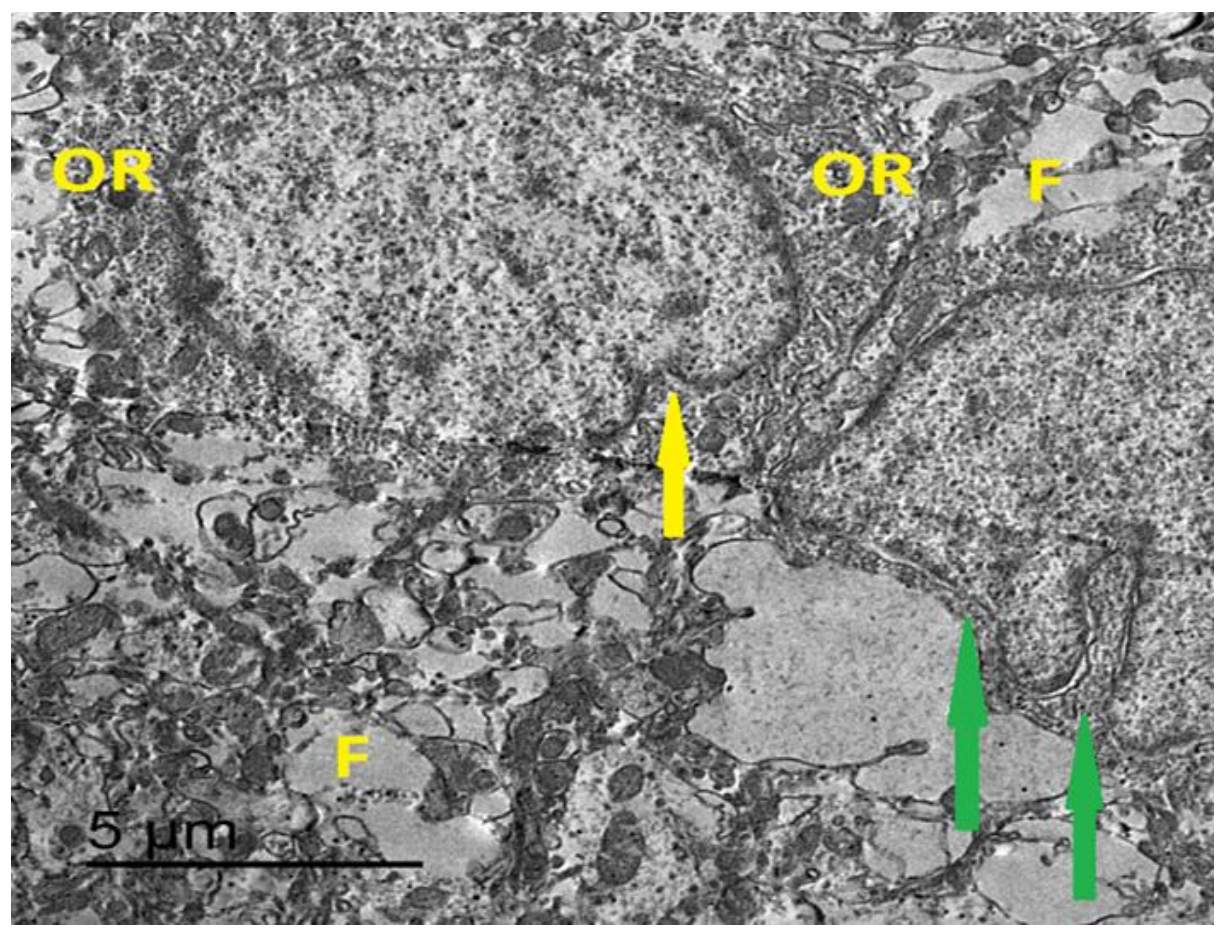

Fig. 15: A photomicrography of ultrathin sections of brain tissue of subgroup 2c (withdrawal of cannabis for 3 days) revealed mild improvement. Some cells restored their normal cytoplasmic organelles (OR); smooth regular nuclear membrane with some indentation (yellow arrow); others still showed degeneration with nuclear membrane folding (green arrow). Edema fluid is still present (F) (EM 1000) 


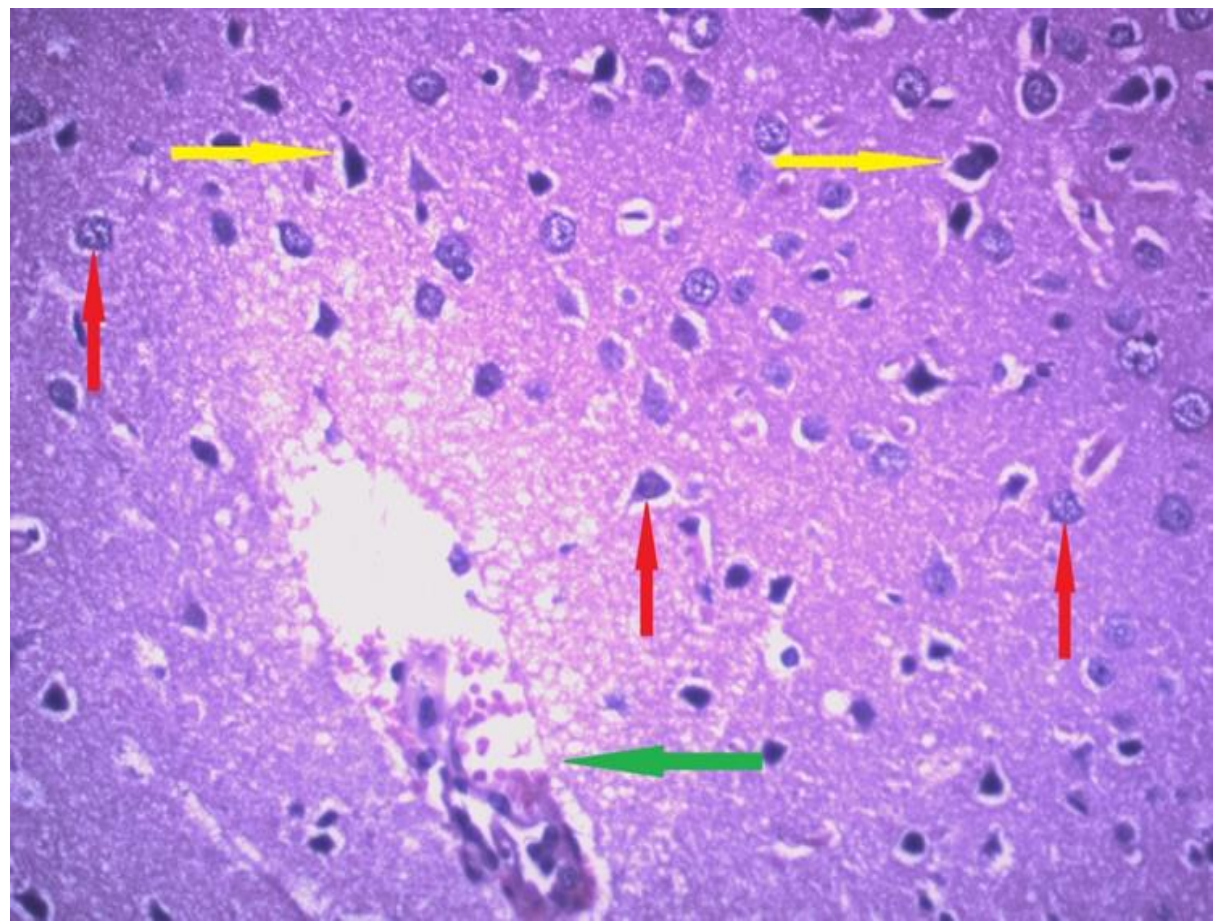

Fig 16: A photomicrography of brain tissue of subgroup 2d (withdrawal of cannabis for 7 days) showing normal neurons (red arrow) while and degenerated neurons (yellow arrow). Notice injury of capillary wall with release of blood outside (green arrow) (H\&E, X 400)

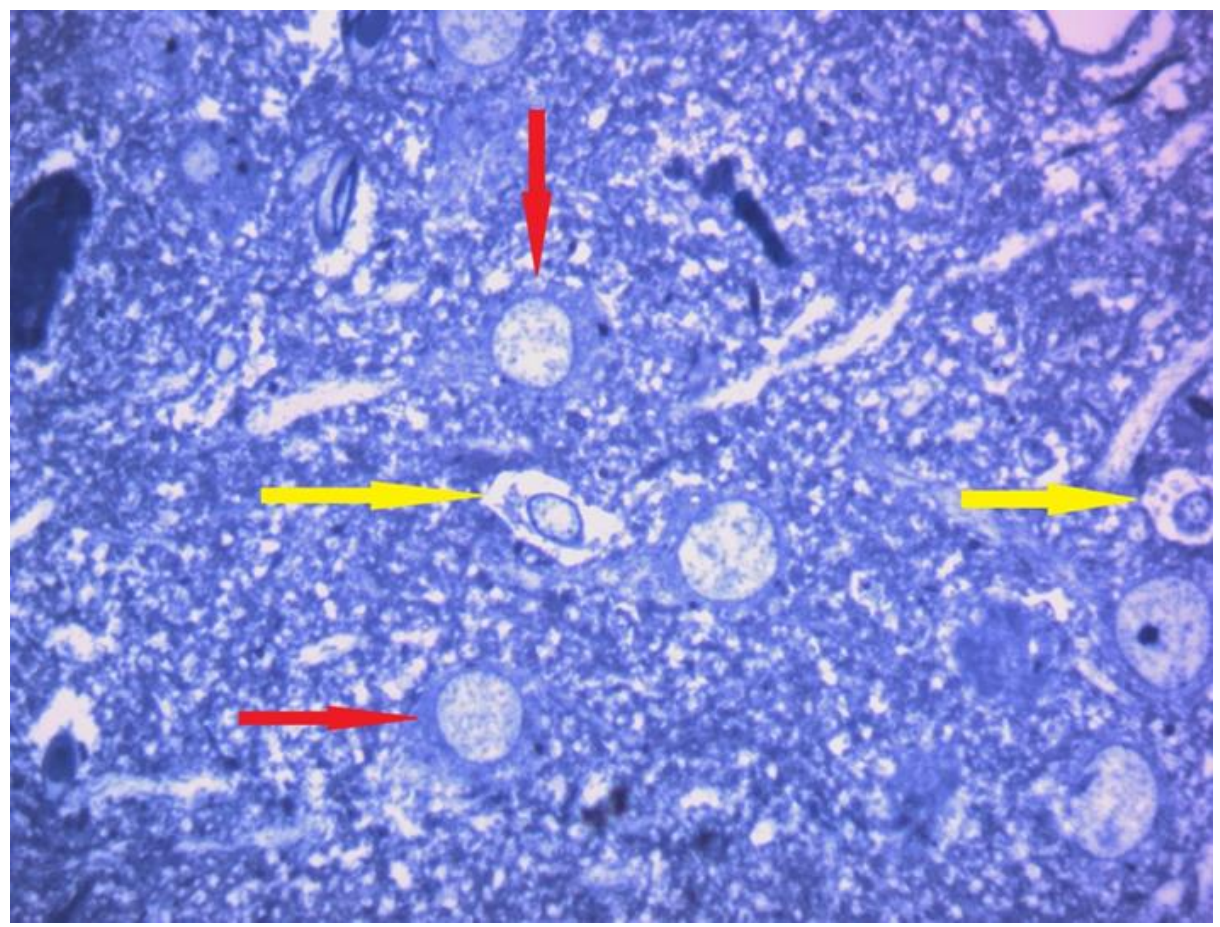

Fig 17: A photomicrography of brain tissue of subgroup 2d (withdrawal of cannabis for 7 days) showing mild to moderate improvement. Most of neurons appear normal (red arrow) while some appear degenerated (yellow arrow) (T.B X 1000) 


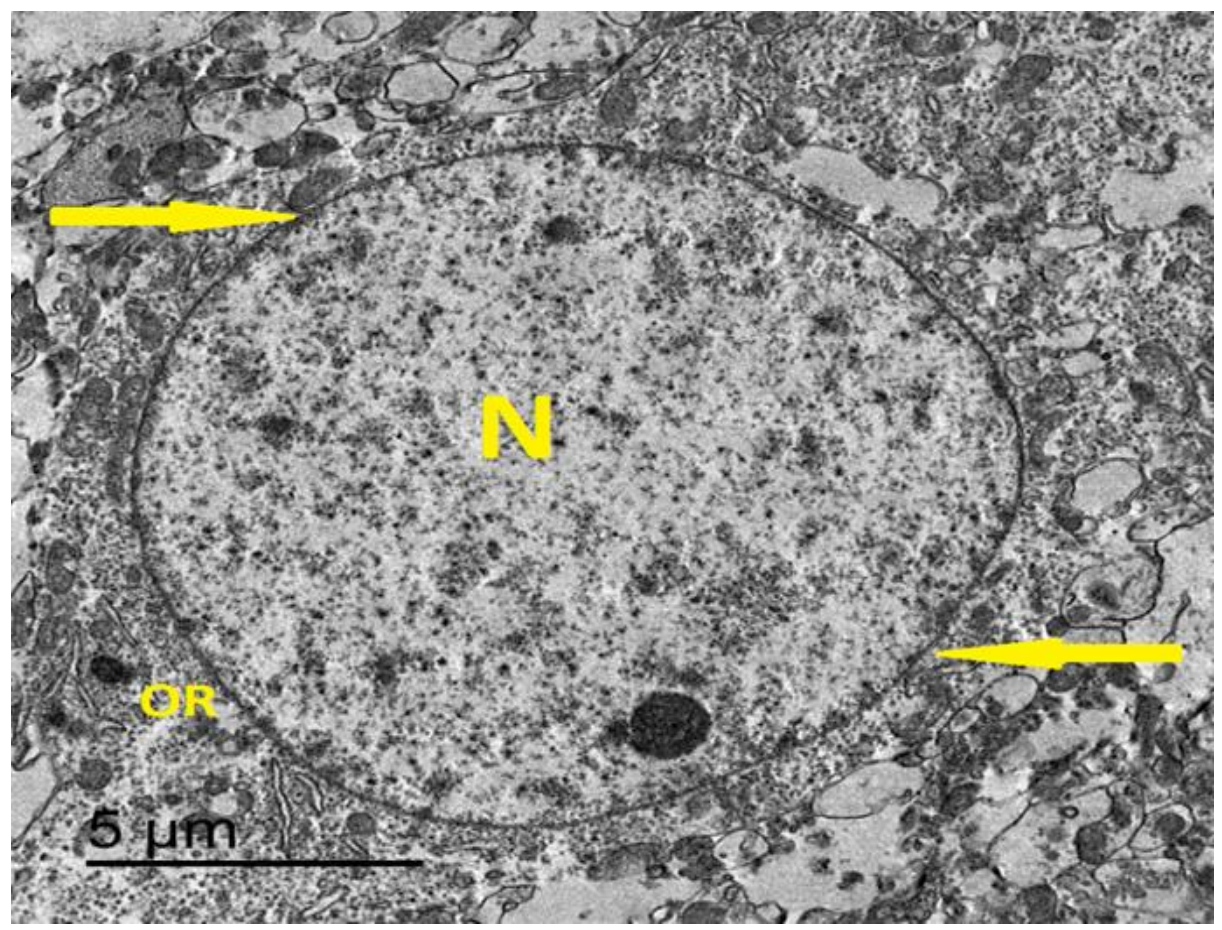

Fig. 18: A photomicrography of ultrathin sections of brain tissue of subgroup $2 d$ (withdrawal of cannabis for 7 days) showing mild to moderate improvement. The neuron appeared with euchromatic nuclei, extended chromatin $(\mathrm{N})$, and smooth regular nuclear membrane (yellow arrow). The cytoplasmic organelles reappeared with good condition (OR) (EM 1000)

\section{Discussion}

The current work aimed to study the toxic effect of long-term cannabis administration on rat behavior, brain dopamine level and histology of the brain tissue.

Albino rats were selected in this study because there was considerable knowledge of this strain and also due to previous studies carried out on it, and its tolerability is very crucial. The albino rat has the capability to provide adequate blood for biochemical assessment (Sengupta, 2013). Male rats had been used to avoid any sex variations due to any hormonal differences (Hammad, 1997).

As regard to weight changes due to long-term cannabis administration cannabis administration; the current study revealed decrease in body weight of rats of subgroup 2a by approximately $10 \%$ at the end of the month from the weight at the start of the experiment; probably due to anorexia and reduction in consumption of food as part of CNS depression (Kirkham, 2005). 49 THC's effect on appetite differs in acute from chronic administration; acute $\Delta 9$-THC produces hyperphagic effects on rats and increased the motivation to food (Jarbe and DiPatrizio, 2005). The effects of excessive $\triangle 9$-THC on body weight might be due to adaptive endocannabinoid signaling down-regulation in the brain. Therefore, even if acute $\Delta 9$-THC administration increases appetite, repeated CB1 receptor activation by $\triangle 9$-THC results in desensitization of CB1 receptors, which may cause $\Delta 9$-THC to produce antagonism effect rather than agonism. The results of the current study were in line with Klein et al., (2011) in their study of acute and chronic 49 -THC effects in rats that showed a significant reduction in body weight during chronic treatment with $\triangle 9$-THC in a similar way to what occurs with other anorexigenic medications.

CNS depression was the main manifestation in $\mathrm{s}$ ubgroup 2a rats as a sign of long-term cannabis administration. CB1 receptor agonists, including $\Delta 9$ THC, cause what has been termed the "cannabinoid tetrad" in rodents which is characterized by catalepsy, hypothermia, anti-nociception (blocking the detection of a painful or injurious stimulus by sensory neurons) and suppression of motor activity (Katsidoni et al., 2013).

CNS depression observed in long-term cannabis administration rat group coincided with Taffe et al., (2015) in their study on rats given doses of $\Delta 9$-THC to determine if combined cannabidiol (CBD) could reverse effects caused by $\triangle 9$-THC; they found that locomotor activity was suppressed by $\triangle 9$-THC administration; and the effects of $\Delta 9$-THC were roughly dose-dependent. Also; Varvel et al., (2005) in their experiment to test whether marijuana's pharmacological activity is caused by THC levels alone or other components contribute to it, had shown that $\triangle 9$-THC decreased mice locomotor activity as well as causing analgesia and hypothermia.

Also; Hložek et al., (2017) in their experiment on rats to study metabolic and behavioural effects of $\Delta 9$ - 
THC and CBD; they found strong sedation and catalepsy occurred after oral administration of THC.

In the present study cannabis withdrawal manifestations (in the form of irritability and aggression) were recorded in subgroup $2 \mathrm{~b}$, peaked in subgroup 2c and diminished in subgroup 2d.

Although the use of cannabinoids, such as marijuana and hashish, was historically considered to be devoid of withdrawal symptoms, it is now known that cannabinoids, indeed, produce clinically significant withdrawal symptoms. It is likely, therefore, that these withdrawal symptoms contribute to cannabis dependence through negative reinforcement processes (Oleson and Cheer, 2012). Human laboratory studies have shown that a cannabinoid withdrawal syndrome has arisen following abrupt discontinuation of chronic oral $\Delta 9$-THC consisting of disturbed sleep, restlessness, irritability, sweating, chills and nausea. It was therefore concluded that physical withdrawal effects on abstinence could contribute to the continued use of marijuana in dependent individuals (Lichtman and Martin, 2002; Allsop et al., 2011). The pharmacokinetic and pharmacodynamic characteristics of the drug, as well as dosing regimen, influence the specific withdrawal syndrome, its intensity and the onset of withdrawal responses. Consequently, withdrawal symptoms are delayed following discontinuation from drugs with a long half-life, such as $\triangle 9$-THC (Lichtman and Martin, 2002); this explains why -in the present study- withdrawal manifestations were most obvious in subgroup 2c, (which was deprived from cannabis for 3 days), compared with subgroup $2 b$ (which was deprived from cannabis for only 1day).

These findings agreed with Budney et al., (2004) who stated that cannabis withdrawal manifestations typically begin 1-2 days after cessation, peaks at 2-6 days and remits at 1-2 weeks. Also; Gonz'alez et al., (2004) in their study on behavioral changes elicited by acute administration of CB1R antagonist to $\triangle 9$-THC tolerant rats, they stated the existence of a withdrawal syndrome in cannabinoidtolerant rats.

The current results demonstrated significant increase in brain dopamine level in rat subgroup 2a (under pharmacological effects of cannabis) compared to control group. This can be explained by the fact that THC administration leads to dopamine accumulation in the NAcc and may be inhibited by CB1 antagonists (Cheer et al., 2004). The current findings agreed with Kuepper et al., (2010) in their review examining the evidence concerning the interactions between THC, endocannabinoids and dopamine in the cortical and subcortical regions implicated in psychosis; they stated that THC acts upon CB1 receptor in the VTA to evoke burst firing leading to dopamine increases in striatal areas and the NAcc.

In the present study; groups of rats suffering cannabis withdrawal (2b, 2c, 2d) showed gradual decrease in dopamine level, until it reached statistically significant decrease in subgroup 2d (withdrawal of cannabis for 7 days) compared with subgroup 2a. This can be explained by cannabis withdrawal marked reduction of electrophysiological activity in NAccprojecting DA containing neurons of the rat midbrain and reduction of DA outflow in the NAcc shell (Spiga et al., 2011). The present findings were in accordance with Oleson and Cheer, (2012) who declared that withdrawal from cannabinoids depresses mesolimbic dopamine function in the same manner as other drugs of abuse.

A strong association between violent aggression and substance abuse with similar neurochemical abnormalities - specifically in the dopaminergic system has been observed in individuals at risk for aggressive behavior as well as substance abuse (Soderstrom et al., 2003). In animal studies, hyperactivity in the dopamine system is associated with increases in impulsive aggression. Studies on aggressive behaviors in rodents showed that elevated dopamine levels have been continuously observed before, during, and following aggressive fights (Seo et al., 2008). In humans, the dopaminergic system has been linked to the recognition and experience of aggression (Rosell and Siever, 2015).

In rat subgroup 2a; brain dopamine level was significantly high compared with control group. Elevated dopamine level in this group was supposed to be associated with violent behavior and aggression; however; aggressive behavior was not prominent in this subgroup except at the time of the next dose i.e. with the onset of withdrawal. This coincides with sense of relaxation, euphoria and being "high" reported by cannabis users. So; it is strongly suggested that aggressive behavior that may occur in chronic cannabis abusers is multifactorial and may be related to other factors besides direct pharmacological effect of cannabis (i.e. elevated dopamine level). This result agrees completely with Goldstien, (1985's) tripartite framework describing the relation between violence and drugs.

In the current study examination of brain in rats groups which received daily oral cannabis dose revealed histological changes in the brain tissues on both light and electron microscopic levels, and these changes go hand by hand with the biochemical assays. The brain is the organ mostly affected by administration of THC because its main effects are mediated through the cannabinoid receptors CB1 that are densely concentrated in brain regions and these receptors are mainly found in axons and nerve terminals and they are presynaptic thus they modulate neurotransmitter release (Iversen, 2003; Yassa et al., 2010). Brain of rats subgroups 2a, 2b, 2c and 2d showed pathological degenerative changes in the brain cerebrum. These degenerative changes can be explained by THC accumulation in neurons and with chronic exposure becomes neurotoxic leading to neuroanatomic abnormalities (Monnet-Tschudi et al., 2008). THC is a potent source of cellular oxidative stress that could contribute to cell injury, metabolic impairments and neuronal damage. THC damage neurons by increasing 
cyclooxygenase (COX) that catalyze the formation of reactive oxygen spices (ROS), it also alters archidonic acid metabolism and increases the production of lipooxygenase products that are prooxidants (Sarafian and Marques, 1999). Oxidative stress produced can also lead to the opening of inter-endothelial junctions and increased vascular permeability (Mittal et al., 2014). This explain the current study evidence of vasculopathy in cannabis treated rats; in the form of disturbance of the tight junction between endothelial cells raveled by EM; with subsequent increase in the vascular permeability and filtration of edema fluid in between the nerve fibers of the white matter.

The degenerative changes observed in the current study as shrunken neurons with irregular cell boundaries and darkly stained nuclei, nuclear membrane folding, chromatolysis, condensed peripheral chromatin, destruction of cellular organelles, multiple vacuoles in the cytoplasm and loss of cell membrane; were reported by Proskuryakov et al.,(2003) and Festjens et al., (2006) as signs of necrosis and apoptosis. Since neurons are permanent cells, they are most susceptible to hypoxic injury as that occurs with cannabis. Cannabis causes significant decrease in oxygen consumption and significant increase in mitochondrial hydrogen peroxide production and so changes in integrated mitochondrial function and inhibitions of mitochondrial respiratory chain (Athanasiou et al., 2007).

Current histopathological findings were in accordance with Yassa et al., (2010) who reported that the brain tissue is the organ mostly affected by cannabis and they found noticeable brain tissue affection in the form of irregular shrunken cells with dense nuclei and vacuolated cytoplasm in all layers. Also; Nafea et al., (2016) found that in cannabis dependent rat group; HX \&E stained sections of rats' brain showed congested meningeal blood vessels, irregular shrunken cells and vacuolated cytoplasm. The cells were surrounded by irregular wide spaces. Also, congested blood vessels and dilated perivascular spaces were present.

Unfortunately, after withdrawal, the complete reversibility wasn't achieved. This was in accordance with Nafea et al., (2016) who stated that in cannabiswithdrawn group; examination of rats' brain still showed some pathological changes represented by inflammatory cellular infiltration, vacuolated cytoplasm and area of gliosis. The partial recovery of brain tissue after cannabis withdrawal could be explained by the function of endocannabinoid system (eCBs). However, non-eCBs independent mechanism is superior in counteracting neuropathological events (Bartsch et al., 2007).

\section{Conclusion}

Long-term cannabis administration causes degenerative pathological changes in the brain, which may explain the literature well documented effect of cannabis on cognition, memory and learning. aggressive behavior was prominent in rat group sacrificed after withdrawal of cannabis rather than rat group sacrificed under the pharmacological effect of cannabis; so; it is strongly suggested that aggressive behavior that may occur in chronic cannabis abusers is multifactorial and may be related to other factors besides direct pharmacological effect of cannabis (i.e. elevated dopamine level).

Also; degenerative histopathological changes didn't completely returned normal; this may indicates the need for longer recovery period after stoppage of cannabis.

\section{References}

Allsop, D.J.; Norberg, M.M.; Copeland, J. et al., (2011): The Cannabis Withdrawal Scale development: patterns and predictors of cannabis withdrawal and distress. Drug Alcohol Depend., 119: 123-129

American Psychiatric Association (2013): Diagnostic and Statistical Manual of Mental Disorders (DSM5®), 5th ed.; 571-4. American Psychiatric Publishing: Washington, DC, USA.

Athanasiou, A.; Clarke, A.B.; Turner, A.E. et al., (2007): Cannabinoid receptor agonist are mitochondrial inibitors: A unified hypothesis of how cannabinoids modulate mitochondrial function and induce cell death. Biochemical and Biophysical Research communications, 364: 131137

Bartsch, A.J.; Homola; G., Biller, A. et al., (2007): Manifestations of early brain recovery associated with abstinence from alcoholism. Brain, 130(1):36-47.

Budney, A.J.; Hughes, J.R.; Moore, B.A. et al., (2004): Review of the validity and significance of cannabis. Am. J. Psychiatry, 161: 1967-1977

Carlton, M.A. (1982): Histopathological techniques. 1st edition. Oxford University Press. New York, Toronto.

Cheer, J.F.; Wassum, K.M.; Heien, M.L.A.V. et al., (2004): Cannabinoids enhance subsecond dopamine release in the nucleus accumbens of awake rats. J. Neurosci, 24: 4393-4400.

Dawson, B. and Trapp, R.G. (2001): Basic and clinical biostatistics: lange medical books. Oxford, London. Boston, McGraw-Hill, Medical Publishing Division. 3rd edition, Chapter 7-9, pages: 161-218.

El-Alfy, A.T.; Ivey, K. and Robinson, K. (2010): Antidepressant-like effect of $\Delta 9$ tetrahydrocannabinol and other cannabinoids isolated from Cannabis sativa L. Pharmacology, Biochemistry and Behavior, 95: 434-442

Fanarioti, E.; Mavrikaki, M.; Panagis, G. et al., (2015): Behavioral and Neurochemical Changes in Mesostriatal Dopaminergic Regions of the Rat after Chronic Administration of the Cannabinoid 
Receptor Agonist WIN55,212-2. International Journal of Neuropsychopharmacology,18(6): 117

Festjens, N.; Vanden Berghe, T. and Vandenabeele, P. (2006): "Necrosis, a well-orchestrated form of cell demise: Signalling cascades, important mediators and concomitant immune response". Biochimica et Biophysica Acta (BBA) - Bioenergetics. Mitochondria: from Molecular Insight to Physiology and Pathology; 1757 (9-10): 13711387

Fitzgerald, K.T.; Bronstein, A.C. and Newquist, K.L. (2013): Marijuana poisoning. Top Companion Anim Med., 28(1):8-12

Goldstein, P.J. (1985): The drugs/violence nexus: a tripartite conceptual framework. Journal of Drug Issues, 15: 493-506.

Gonz'alez, S.; Fernández-Ruiz, J.; Di Marzo, V. et al., (2004): Behavioral and molecular changes elicited by acute administration of SR141716 to 9tetrahydrocannabinol-tolerant rats: an experimental model of cannabinoid abstinence. Drug and Alcohol Dependence, 74: 159-170

Hammad, S.A. (1997): Experimental study on toxicity of acetaminophen in normal and bilharzially infested animals. Doctorate thesis in forensic medicine and toxicology. Faculty of medicine, Menoufia University: 290-294

Hložek, T.; Uttl, L.; Kadeřábekc, L. et al., (2017): Pharmacokinetic and behavioural profile of $\mathrm{THC}$, $\mathrm{CBD}$, and $\mathrm{THC}+\mathrm{CBD}$ combination after pulmonary, oral, and subcutaneous administration in rats and confirmation of conversion in vivo of CBD to THC. European Neuropsychopharmacology, 27: 1223-1237

Iversen, L. (2003): Cannabis and the brain. Brain., 126(6):1252-70.

Jaffe, M. (1969): Jaffe Method. In Manual clinical laboratory diagnosis. Levinson C, Mac Fate C. 7th edition. Page: 117.

Jarbe, T.U. and DiPatrizio, N.V. (2005): Delta9-THC induced hyperphagia and tolerance assessment: interactions between the $\mathrm{CB} 1$ receptor agonist delta9-THC and the CB1 receptor antagonist SR141716 (rimonabant) in rats. Behav Pharmacol, 16(5-6):373-80.

Karnovsky, M.J. (1965): A formaldehyde -glutaraldehyde fixative of high osmolality for use in electron microscopy. J. Cell Biol, 27, 137-138.

Katsidoni, V.; Kastellakis, A. and Panagis, G. (2013): Biphasic effects of Delta 9- tetrahydrocannabinol on brain stimulation reward and motor activity.Int.J.Neuropsychopharmacol., 16: 2273 2284.

Kiernan, J.A. (1999): Histopathological and histochemical methods: theory and practice. 3rd edition. Page: 105. Buterworth Heimann.
Kirkham, T.C. (2005): Endocannabinoids in the regulation of appetite and body weight. Behav Pharmacol, 16(5-6):297-313.

Klein, C.; Karanges, E.; Spiro, A. et al., (2011): Cannabidiol potentiates delta (9)tetrahydrocannabinol (THC) behavioural effects and alters THC pharmacokinetics during acute and chronic treatment in adolescent rats. Psychopharmacology (Berl), 218(2): 443-57

Kuepper, R.; Morrison, P.D.; Os, J.V. et al., (2010): Does dopamine mediate the psychosis-inducing effects of cannabis? A review and integration of findings across disciplines. Schizophrenia Research, 121: 107-117

Lichtman, A.H. and Martin, B.R. (2002): Marijuana Withdrawal Syndrome in the Animal Model. Journal of Clinical Pharmacology, 42:20S-27S

Mittal, M.; Siddiqui, M.R.; Tran, K. et al., (2014): Reactive Oxygen Species in Inflammation and Tissue Injury Antioxidants \& Redox Signaling, 20(7): 1126- 1176

Monnet-Tschudi, F.; Hazekamp, A.; Perret, N. et al., (2008): Delta-9-tetrahydrocannabinol accumulation, metabolism and cell-type-specific adverse effects in aggregating brain cell cultures. Toxicol Appl Pharmacol, 228:8-16.

Nafea, O.E; ElKhishin IA, Awad OA et al., (2016): A study of the neurotoxic effects of tramadol and Cannabis in adolescent male albino rats Int $\mathrm{J}$ Sci Rep., 2(7):143-154

Nagai, H.; Egashira, N.; Sano, K. et al., (2006): Antipsychotics improve Delta 9tetrahydrocannabinol- induced impairment of the prepulse inhibition of the startle reflex in mice. Pharmacol.Biochem.Behav.; 84, 330-336.

Oleson, E.B. and Cheer, J.F. (2012): A Brain on Cannabinoids: The Role of Dopamine Release in Reward Seeking. Cold Spring Harbor Perspectives in Medicine, 2(8): a012229-a012229.

Proskuryakov, S.Y.; Konoplyannikov, A.G. and Gabai, V.L. (2003): "Necrosis: a specific form of programmed cell death?". Experimental Cell Research, 283 (1): 1-16.

Radwan, M.M.; ElSohly, M.A.; El-Alfy, A.T. et al., (2015): Isolation and Pharmacological Evaluation of Minor Cannabinoids from High Potency Cannabis sativa. J Nat Prod., 78(6): 1271-6.

Ramesh, D.; Schlosburg, J.E.; Wiebelhaus, J.M.; et al., (2011): Marijuana dependence: not just smoke and mirrors. ILAR journal / National Research Council, Institute of Laboratory Animal Resources., 52: 295-308.

Reynolds, E.S. (1963): The use of lead citrate at high pH as an electron-opaque stain in electron microscopy. J. Cell Biol., 17, 208-212

Rosell, D.R. and Siever, L.J. (2015): The neurobiology of aggression and violence. CNS Spectrums, 20: 254-279 
Sarafian, T.A. and Marques, J.A. (1999): Oxidative stress produced by marijuana smoke: an adverse effect enhanced by cannabinoids. Am.J.Respir. CellMol. Biol., 20(6): 1286- 1293.

Sengupta, P. (2013): The Laboratory Rat: Relating Its Age With Human's. Int J Prev Med., 4(6): 624630.

Seo, D.; Patrick, C.J. and Kennealy, P.J. (2008): Role of Serotonin and Dopamine System Interactions in the Neurobiology of Impulsive Aggression and its Comorbidity with other Clinical Disorders Aggress Violent Behav., 13(5): 383-395.

Smith, J.E.; Lane, J.D.; Shea, P.A. et al., (1975): A method of concurrent measurement of picomol quataties of acetylcholine, choline, dopamine, norepinephrine, serotonin, 5- hydroxytryptophan, tyrosine, glycine, aspartate, glutamate, analine and gamma-amino-butyric acid in single tissue samples from different areas of rat central nervous system. Anal Biochem., 64: 149- 169

Soderstrom, H.; Blennow, K.; Sjodin, A.K. and Forsman, A. (2003): New evidence for an association between the CSF HVA:5-HIAA ratio and psychopathic traits. Journal of Neurology Neurosurgery and Psychiatry., 74:918-921.

Spiga, S.; Lintas, A. and Diana, M. (2011): Altered Mesolimbic Dopamine System in THC Dependence. Current Neuropharmacology, 9: 200204
Taffe, M.A.; Creehan, K.M. and Vandewater, S.A. (2015): Cannabidiol fails to reverse hypothermia or locomotor suppression induced by $\Delta 9$ tetrahydrocannabinol in Sprague-Dawley rats. British Journal of Pharmacology, 127(7): 1-9

Varvel, S.A.; Bridgen, D.T.; Tao, Q. et al., (2005): 9Tetrahydrocannbinol Accounts for the Antinociceptive, Hypothermic, and Cataleptic Effects of Marijuana in Mice. The journal of pharmacology and experimental therapeutics, 314(1): 329- 337.

Volkow, N;D.; Wang, G.J.; Fowler, J.S. et al., (2011): Addiction: beyond dopamine reward circuitry. Proc. Natl Acad. Sci. USA 108: 15037-15042

Wiley, J.L. and Burston, J.J. (2014): Sex differences in Delta (9)-tetra- hydrocannabinol metabolism and in vivo pharmacology following acute and repeated dosing in adolescent rats. Neurosci.Lett., 576: 51-55.

Yassa, H.A., Dawood, A.E.A., Shehata, M.M. et al., (2010): Subchronic toxicity of cannabis leaves on male albino rats. Human and Experimental Toxicology, 29(1): 37-47 


\section{دراسة تأثير التعاطى المتكرروكذلك تأثير الإنسحاب للحشيش على أنسجة المخ لذكور الفئران البيضاء البالغة: دراسة هستولوجية وبيوكيميائية الأبية}

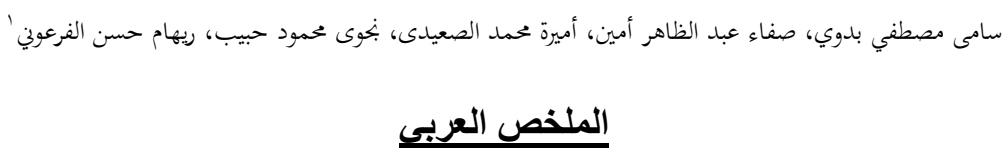

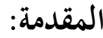

يجتل الحشيش مكانة أكثر مخدرات تعاطيًا انتشارًا في مصر. قد يتسبب تعاطي القنب المزمن في تغيرات مرضية تنكسية في الدماغ ، كما أن تأثير القنب على الإدراك

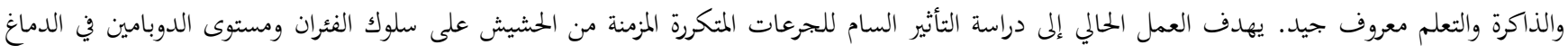
والنغيرات النسيجية المرضية للدماغ.

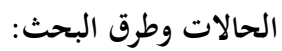

دراسة بحريبية لتأثير الحشيش علي ذكور الجحث: الجرذان البيضاء البالغين، وقد تم اختيار الحشيش بعد انتهاء الجزء الأول من الدراسة كأكثر مواد الإعتماد شيوعا بين الحالات.

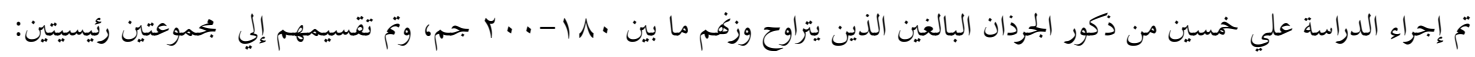
بحموعة ا (الضابطة): تتكون من عشرة فئران

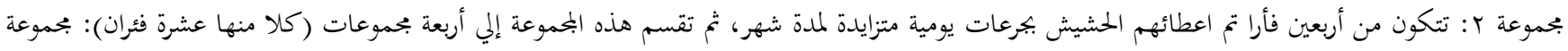

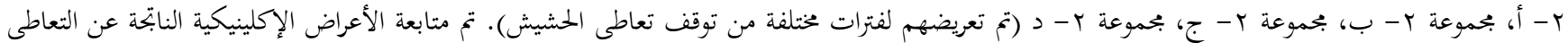

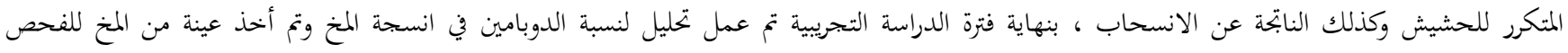
الهستولوجي باستخدام الميكروسكوب الضوئى الميكروسكوب الالكتروني.

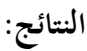
إكلينيكيا وجد أن الأعراض الأساسية لتأثير التعاطى المتكرر للحشيش ف محموعة ب-أ كان تثبيط الجهاز العصبي المركزي، بينما الأعراض الرئيئية التي تم ملاحظتها

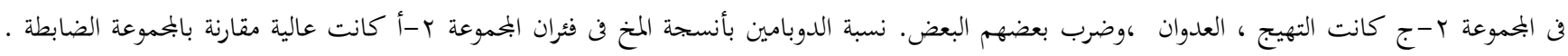
أظهر الفحص البُهري لخلايا المخخ ضموروانحلال بالخلايا العصبية. الإستنتاج:

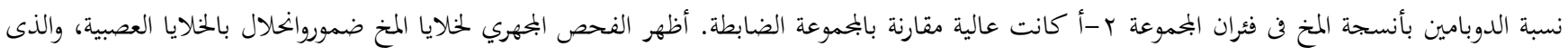
غالبا ما يحتاج إلى فترات تعافن طويلة. 